Int. J. Dev. Biol. 61: 479-493 (2017)

doi: 10.1387/ijdb.170110jh

\title{
Beyond the sea: Crepidula atrasolea as a spiralian model system
}

\author{
JONATHAN Q. HENRY*,1, MARYNA P. LESOWAY ${ }^{1}$, KIMBERLY J. PERRY ${ }^{1}$, C. CORNELIA OSBORNE ${ }^{1}$, \\ MARTY SHANKLAND ${ }^{1}$ and DEIRDRE C. LYONS ${ }^{*}, 2$ \\ ${ }^{1}$ University of Illinois, Department of Cell \& Developmental Biology, Urbana, IL and \\ ${ }^{2}$ Scripps Institution of Oceanography, University of California, San Diego, La Jolla, CA, USA
}

\begin{abstract}
This paper introduces the black-footed slipper snail, Crepidula atrasolea, as a new model for biological studies in the Spiralia. $C$. atrasolea is a calyptraeid gastropod, and congener of the Atlantic slipper snail, $C$. fornicata. Like $C$. fornicata, $C$. atrasolea shares a sedentary, filter-feeding, protandrous lifestyle, but is preferable as a developmental model because of its short generation time, year-round reproduction, and direct development. In our lab, individuals go from egg to reproductive females in under six months, as compared to an estimated 1-2 years for $C$. fornicata. Here we provide details for collecting and transporting animals, setting up inland aquaria, and maintaining laboratory colonies of $\boldsymbol{C}$. atrasolea. We also describe early development, which is similar to that in other calyptraeids. Females brood encapsulated embryos for three weeks, which hatch as "crawlaway" juveniles. We also present a developmental transcriptome for $C$. atrasolea, covering early cleavage through late organogenesis stages, as a useful tool for future studies of gene expression and function. We provide this information to the broader developmental community to facilitate widespread use of this system.
\end{abstract}

KEY WORDS: Mollusca, Gastropoda, Spiralia, aquaculture, development, transcriptome

\section{Background}

In the early history of developmental biology, lophotrochozoan animals including the gastropod snail, Crepidula fornicata, were widely used for biological study (Conklin, 1897; Wilson, 1892). They played important roles in understanding embryonic cell lineage and the origins of the germ layers, and helped establish the field of evolutionary developmental biology (Wilson, 1898). However, short generation times, ease of laboratory culture and genetic tractability ultimately made other species, such as Drosophila, zebrafish, $C$. elegans, and mice more attractive models to developmental biologists. It was not until molecular phylogenies revolutionized our view of the tree of life that renewed interest emerged in the third major branch of the Bilateria, the Lophotrochozoa or Spiralia (Halanych et al., 1995; Tessmar-Raible, 2003; Edgecombe et al., 2011). The Lophotrochozoa/Spiralia are generally construed to comprise 14 phyla (such as the Annelida, Mollusca, Nemertea, and Platyhelminthes) that include many representative species exhibiting 1) spiral cleavage during early development, 2) trochophore larvae bearing a prominent circumferential ciliated band involved in feeding and swimming, and/or 3) a feeding apparatus called the lophophore (reviewed in Henry, 2014), as well as other characteristics. Despite their abundance, the Spiralia remain poorly represented as modern developmental models. If the goal of evolutionary and developmental biology is to understand how the diversity of biological forms evolved, we cannot ignore the tremendous diversity of body plans represented by this group.

Marine gastropod molluscs in the genus Crepidula have been used as subjects for developmental studies for over 100 years, beginning with Conklin's early cell lineage work at the Marine Biological Laboratory in Woods Hole (Conklin, 1897). There are around 120 extant members of the Calyptraeidae and within this family there are at least 45 accepted species of Crepidula (Collin, 2003a). Calyptraeids have contributed to our understanding of a broad range of subjects, including development, evolution, larval biology and metamorphosis, invasion biology, sequential hermaphroditism, and population genetics (reviewed in Henry et al., 2010a; Henry and Lyons, 2016).

All calyptraeids are sedentary filter feeders. Phytoplankton are collected by the ciliary action of the gill, and algae are wound into

\footnotetext{
*Address correspondence to: Jonathan Q. Henry. University of Illinois, Department of Cell \& Developmental Biology, 601 S. Goodwin Ave., Urbana, IL 61801 , USA. E-mail: j-henry4@illinois.edu (ID) http://orcid.org/0000-0003-0537-1014 or Deirdre C. Lyons. Scripps Institution of Oceanography, University of California, San Diego, 9500 Gilman Drive, La Jolla, CA 92093, USA. E-mail: d1lyons@ucsd.edu - (iD http://orcid.org/0000-0002-2644-5214
} 

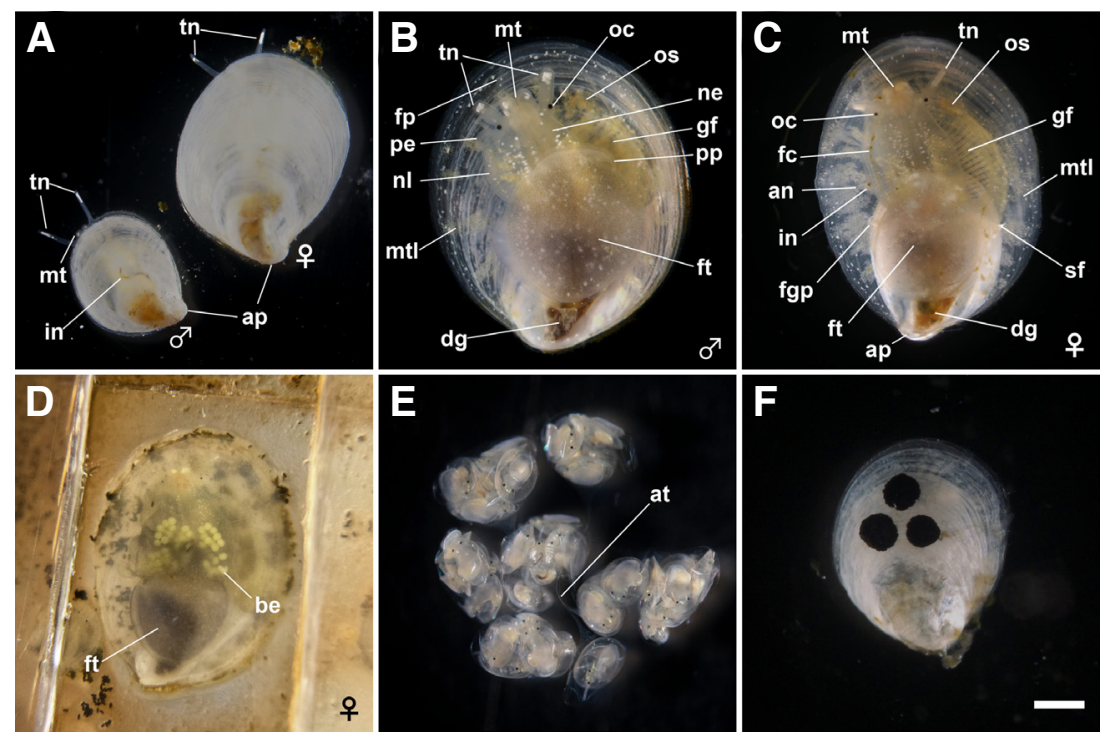

Fig. 1. Adult anatomy and brooding in C. atrasolea. (A) Dorsal view of adult male and female snails. (B) Ventral view of adult male. (C) Ventral view of adult female. (D) Ventral view of female brooding embryos. (E) Egg sacs containing advanced juvenile snails almost ready to hatch. (F) Juvenile snail marked for identification with india ink dots on the dorsal surface of the shell. an, anus; ap, apex; at, attachment thread; be, brooded embryos; dg, digestive gland; $f_{c}$, food cord; fgp, female gentile papillum; fp, food pouch; ft, foot; gf, gill filliments; in, intestine; $m t$, mouth; $m t l$, mantle; ne, neck, $n l$, neck lobe; oc, ocellus; os, osphradium; pe, penis; pp, propodium; sf, shelf; th, tentacle; Scale bar in (F) represents: $1500 \mu \mathrm{m}$ for $(A, C, D), 500 \mu \mathrm{m}$ for $(B, F)$ and $400 \mu \mathrm{m}$ for $(E)$. a mucus string that is regularly ingested (Chaparro et al., 2002) (Fig. 1C). Calyptraeids are protandrous hermaphrodites, i.e., all individuals change sex from male to female as they increase in age and size during their lifetime (Coe, 1936; Collin et al., 2005). The timing of this transition is strongly influenced by social environment, in addition to size and feeding state (Coe, 1938; Collin, 1995; Hoagland, 1978), and is controlled by physical contact between individual animals (Cahill et al., 2015; Carrillo-Baltodano and Collin, 2015). Calyptraeid life history is diverse, and includes indirect development with planktotrophy (swimming and feeding larvae), lecithotrophy (swimming, non-feeding larvae), direct development that may include feeding on nutritive eggs or embryos (oophagy or adelphophagy) and poecilogony (transition between direct and indirect development in a single species) (Collin, 2003c; McDonald et al., 2014; see Table 1). This diversity of larval developmental types has made the group of interest for studies of evolution. These studies have revealed that in at least one case, a swimming, feeding larva has re-evolved from a clade of direct developers (Collin, 2004; Collin et al., 2007).

The biology of these snails has potential for widespread application to studies of developmental biology, including larval development and metamorphosis. Furthermore, comparative studies of the development of different species will shed light on the mechanisms that underlie evolutionary transitions between different modes of development. As these snails are sequential, protandric hermaphrodites they also provide an excellent opportunity to understand the mechanisms regulating sexual development and sex determination (Fig. 1 A-C). Some Crepidula species (e.g., $C$. fornicata and $C$. onyx) are highly invasive and studies have examined their population dynamics (Cahill and Viard, 2014; Dupont et al., 2007; Hoagland, 1985; Riquet et al., 2013, 2016; Woodruff et al., 1986). Perhaps, an understanding of development can be applied to control these snails. In contrast, $C$. fornicata are also desired as a source of food, and studies may lead to more effective means for their aquaculture.

In recent years calyptraeids, particularly the Atlantic slipper limpet C. fornicata (Linnaeus, 1758), have emerged as models of lophotrochozoan development (Henry et al., 2010a; Henry and Lyons, 2016). Conklin first elucidated fate maps of $C$. fornicata (Conklin, 1897), which have been refined and expanded upon with modern cell lineage studies (Hejnol et al., 2007; Lyons et al., 2012, 2015). Embryos and eggs of Crepidula are naked (without a vitelline envelope), and readily accessible for experimental manipulation. One can carry out in vivo, time-lapse imaging to study

TABLE 1

\section{LIFE HISTORY PARAMETERS OF SELECTED CREPIDULA SPECIES}

\begin{tabular}{|c|c|c|c|c|c|c|}
\hline Species & Mode of Development & Reproductive Period & Egg Size $(\mu \mathrm{m})$ & Hatching Size $(\mu \mathrm{m})$ & Time to Hatching (days) & Time to Female Maturity (days) \\
\hline Crepidula adunca & direct & seasonal & $240-420$ & $1000-2700$ & $120,12^{\circ} \mathrm{C}^{1}$ & - \\
\hline Crepidula atrasolea & direct & year-round & $315-355$ & $900-1002$ & $21-23,20^{\circ} \mathrm{C}$ & $180,20-27^{\circ} \mathrm{C}$ \\
\hline Crepidula convexa & direct & seasonal & $280-320$ & $900-1080$ & $21,20^{\circ} \mathrm{C}$ & 180, ambient $^{2}$ \\
\hline Crepidula depressa & indirect (planktotrophic) & - & - & 255 & - & - \\
\hline Crepidula fornicata & indirect (planktotrophic) & seasonal & $160-180$ & $445-489$ & 28 , ambient ${ }^{3,4}$ & $240-377,4.5-25^{\circ} \mathrm{C}^{5}$ \\
\hline Crepidula naticarum & indirect (planktotrophic) & - & 164 & 275 & - & - \\
\hline Crepidula navicella & direct (adelphophagic) & year-round & $150-182^{6}$ & $957-977^{7}$ & $21,20^{\circ} \mathrm{C}^{6}$ & - \\
\hline Crepidula norrisiarum & direct & - & $498 \pm 104$ & $1243 \pm 116$ & - & - \\
\hline Crepidula onyx & indirect (planktotrophic) & - & $150-180$ & $297 \pm 16.5$ & 21, ambient $^{8}$ & - \\
\hline Crepidula plana & indirect (planktotrophic) & seasonal & $130-140$ & 300 & 28, ambient $^{3}$ & - \\
\hline Crepidula ustulatulina & indirect (lecithotrophic) & year-round ${ }^{9}$ & $300-340$ & $630-840$ & $19,23^{\circ} \mathrm{C}^{7}$ & $110-140,23-28^{\circ} \mathrm{C}^{10}$ \\
\hline
\end{tabular}

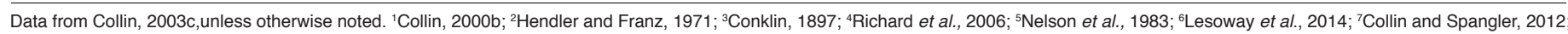
${ }^{8} \mathrm{Coe}, 1949 ;{ }^{9} \mathrm{Collin}, 2010 ;{ }^{10} \mathrm{Collin}$ and Salazar, 2010. Data for additional species can be found in Collin, 2003c. 
TABLE 2

\section{GENOMIC RESOURCES AVAILABLE FOR CREPIDULA SPECIES}

\begin{tabular}{|c|c|c|c|c|}
\hline Species & Resource Type & Developmental Stage & Reference & Resource Availability \\
\hline \multirow[t]{6}{*}{ Crepidula fornicata } & EST Database: 454 GS FLX & $0-5$ day embryos & Henry et al. (2010b) & NCBI SRA SRP002109* \\
\hline & EST Database: Illumina HiSeq 2000 & cleavage -veliger & Perry et al. (2015) (C. Grande) & - \\
\hline & EST Database: Illumina HiSeq 1000 & early cleavage (10-40 hours post fertilization) & Perry et al. (2015) (J. Smith) & - \\
\hline & Genotype by Sequencing: Illumina HiSeq 2000 & Adults, 8 individuals & Romiguier et al. (2014) & NCBI SRA SRP042651 \\
\hline & Microsatellites & Adults & Riquet et al. (2011) & JK312475- JK312486 \\
\hline & Genotype by Sequencing: Illumina HiSeq 2500 & Adults, $20-26$ individuals in 4 populations & Cahill and Levinton (2016) & NCBI SRA SRP058970 \\
\hline \multirow[t]{2}{*}{ Crepidula convexa } & Microsatellites & Adults & Daguin-Thiebaut et al. (2009) & EU573967-EU573977 \\
\hline & Genotype by Sequencing: Illumina HiSeq 2500 & Adults, $20-26$ individuals in 4 populations & Cahill and Levinton (2016) & NCBI SRA SRP058970 \\
\hline Crepidula coquimbensis & Microsatellites & Adults and embryos & Brante et al. (2011) & EF160099-EF160108 \\
\hline Crepidula navicella & EST Database: Illumina HiSeq 2000 & $7-8$ days post laying & Lesoway et al. (2016) & NCBI SRA SRP068776 \\
\hline Crepidula plana & Genotype by Sequencing: Illumina HiSeq 2000 & Adults, 2 individuals & Romiguier et al. (2014) & NCBI SRA SRP042651 \\
\hline
\end{tabular}

*http://www.life.illinois.edu/henry/crepidula_databases.html

morphological events during prolonged development (Lyons et al., 2015). Several EST libraries are also now available to characterize early gene expression (Henry et al., 2010b, see Table 2). Aspects of gene expression and function have been explored using various tools, including key developmental genes like beta-catenin (Henry et al., 2010c) and MAPK (Henry and Perry, 2008). More recent work sets the stage to examine gene regulatory networks involved in gastrulation and germ layer specification (Lyons et al., 2015; Perry et al., 2015). Finally, gene editing with CRISPR/Cas9, has recently been demonstrated in one Crepidula species, making these animals powerful models for functional studies to understand spiralian development (Perry and Henry, 2015).

On the other hand, some aspects of the life cycle of $C$. fornicata present hurdles for long term studies, particularly those involving juvenile and adult snails (see comparisons in Table 1). As a Northern temperate species, development is slower, reproduction is seasonally restricted, and genetic crosses are prohibitively timeconsuming. Furthermore, C. fornicata is an indirect developer, and work with juvenile and adult stages requires tedious rearing of swimming, feeding larvae. These traits make it more difficult to rear inbred or transgenic lines of $C$. fornicata.

We have therefore developed a congener, the "black footed" slipper snail Crepidula atrasolea Collin, 2000, as a laboratory-based model to augment the Crepidula system (Fig. 1 A-F). In addition to all the advantages outlined above for $C$. fornicata, $C$. atrasolea is a Southern, warm-water species with more rapid development and relatively short generation time (approximately six months from egg to egg, Table 1, Henry et al., 2010a). Animals are reproductive year round, and they are readily reared in inland aquaria with artificial seawater. In nature, $C$. atrasolea is amenable to large variation in salinity and temperature (Collin and Griffin, 2005). Their small adult size (shells reaching 1-2 cm long in the lab) allows large numbers of animals to be kept in a limited space (Fig. $1 \mathrm{~A}-\mathrm{F})$. As a direct developer, C. atrasolea produces crawl-away juveniles (Collin, 2000a), so there is no need to provide external food sources prior to reaching juvenile stages (Table 1, Fig. $1 \mathrm{E}-\mathrm{F}$ ). Hence, they are particularly advantageous for studies of juvenile and adult development, and offer the ability to rear inbred lines (e.g., transgenic lines). Here we describe in detail how to collect, care for and feed the adult snails. In addition, we describe early development and how to culture and raise successive generations of embryos, juvenile and adult snails using closed aquaria. Finally, we present the developmental transcriptome of $C$. atrasolea as a valuable tool for future studies of gene expression and function in this model.

\section{Setting up closed marine aquaria}

If one is located at a marine lab with fresh running sea water, these snails can be kept in aquaria or sea tables; however, adequate precautions should be taken not to introduce animals to non-native habitats, as some other species are known to be highly invasive (Henry and Lyons, 2016). For inland labs, the animals can be maintained easily in closed marine aquaria (Fig. 2 A-B). While there are many publications describing how to set up closed marine aquaria, we provide details here as to exactly how we established our systems. A 30-gallon marine aquarium, which measures 36 inches wide $(91 \mathrm{~cm})$, by 12 inches deep $(30 \mathrm{~cm})$, and 17 inches tall $(43 \mathrm{~cm})$, is sufficient to maintain hundreds or even thousands of snails (Aqueon 30 gallon Breeder, Central Aquatics, Central Garden and Pet Co., Franklin, WI.). Aquaria should be prepared in advance of receiving animals to ensure that the biological filter is well established. Filtration is accomplished using a biological under gravel filter bed (Fig. 2A, Lees Premium Under Gravel Filters, product number 13158 , Lee's Aquarium and Pet Products, UPC code 10838 13158, San Marcos, CA). When installing the filter plate make sure that the slots in the bottom grating are open and free of any plastic flashing that may remain from the manufacturing process. Any flashing can be removed with a razor blade. Do not use any activated carbon filter cartridges that may be supplied with these filters. The overlying substrate consists of a three inch thick bed of crushed sea shells or coral (such as Nature's Ocean Prewashed Atlantic Crushed Coral, World Wide Imports, Ent., Inc., Ft. Lauderdale, FL UPC Code 29904 10351). It takes 40-60 lbs. of crushed material for a 30 gallon tank (Fig. 2 A-B). The crushed shells provide a substrate on which the nitrifying bacteria will grow, and contain calcium carbonate, which helps buffer the alkalinity of the tank. The shells must first be rinsed thoroughly in a plastic tub several times in tap water, until the water runs clean, to remove any fine dust, plant material and other debris. Wash the shells until the water is no longer cloudy. Once rinsed, drain the shells well and spread them evenly over the plastic filter plate at the bottom of the aquarium.

Next, artificial sea water is prepared using Reef Crystals Instant Ocean sea salts following the manufacturer's instructions (Spectrum Brands, Inc. Blacksburg, VA, UPC code 51378 01800) and added to the tank (Fig. 2 A-B). We have found that sea water prepared 
using regular Instant Ocean sea salts is not optimal for the development of these snails, as some shell abnormalities appeared during embryonic development. Reef Crystal Instant Ocean sea salts contain additional calcium and other trace elements, and do not cause any shell abnormalities. Though not recommended, one can use tap water to prepare the sea water, but tap water must first be de-chlorinated. Tap water may contain other agents that can be toxic to marine life. Instead, we use reverse osmosis (RO) or deionized (DI) water. If one uses RO or DI water to make up the sea salts, it is advisable to add a conditioner to help buffer the water (we add $125 \mu$ l per liter of Seachem Replenish, Seachem laboratories Madison, GA. UPC code 00116 14760). The pH should be 8.3. Salinity must be adjusted and monitored every few days using a hydrometer or a refractometer, to a specific gravity of 1.024 (see additional comments below).

For effective biological filtration, it is essential that one achieve good water flow through the filter bed. As described by Spotte (1970), efficient water flow is related to several factors. One factor is the number and size of the bubbles produced by the air stones located in the airlifts (Fig. 2A). A large quantity of extremely fine bubbles is desired. These also ensure for more efficient oxygenation of the sea water. Balsa wood or sintered glass air stones work best. Air stones will need to be replaced every 4- 6 weeks, whenever the water flow is noticeably decreased. Unlike balsa wood aerators, sintered glass air stones can be rejuvenated, and reused almost indefinitely (Kordon Mist Air, fine bonded glass bead air stones, Novalek, Inc., Oakland, CA, UPC code 48054 62503). To restore these air stones they simply need to be rinsed and allowed to thoroughly dry. One problem is that the small plastic stems may become loose. Silicone aquarium cement can be used to re-secure the stems in the air stones. To prevent the air stones from rising in the airlifts, use rigid plastic tubing. Flexible plastic tubing should be used to supply the air from the air pump to these rigid tubes (Fig. 2A). Keep these lines as short as possible. Place the air stones inside the airlifts so that they are hovering just under the top surface of the crushed shell substrate; however, do not place the air stones too low, so as not to inject air under the filter plate. A heavy duty air pump is essential to ensure long life and ample airflow (Coralife SL-65 Super Luft Pump, Central Aquatics, Franklin, WI, UPC code 96316 01657). Air pumps must be mounted on a shelf located above the top level of the tank water to prevent back siphoning should the power fail (Fig. 2A). A tight fitting hinged glass lid must be placed on the tank to limit water loss due to evaporation and spray (Aqueon Versa Top for the Aqueon 30 gallon Breeder, product number 100129040, Fig. 2A, UPC code 15905 29040, Central Aquatics, Central Garden and Pet Co., Franklin, WI). Any openings in the rear plastic section of these lids should be made as small as possible to snuggly fit the rigid air tubing and the electrical cord for the heater.

It is recommended that water temperature be maintained at $27^{\circ} \mathrm{C}$. This is accomplished using a submerged heater, such as an Eheim 3617 (200 watt heater, or one sized appropriately for that of the tank, Eheim Jäger, Germany, Product number 3617010, UPC code 4011708361214), which is simply attached to the inside, back wall of the tank using the included suction cups (Fig. 2 A-B). To
A
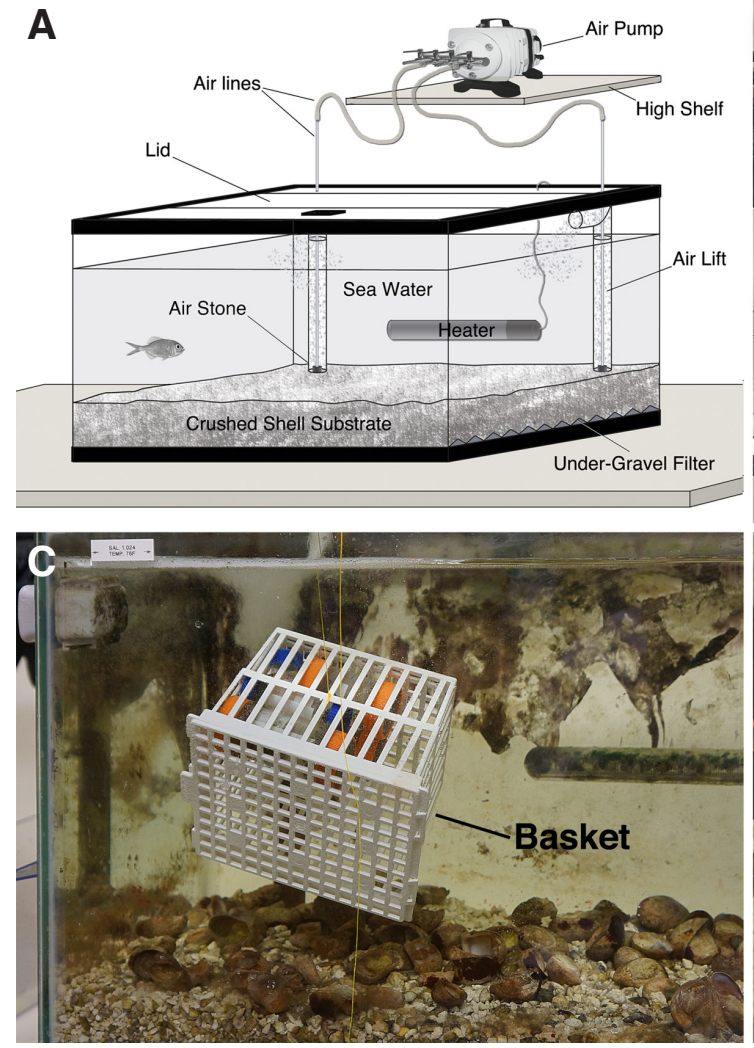
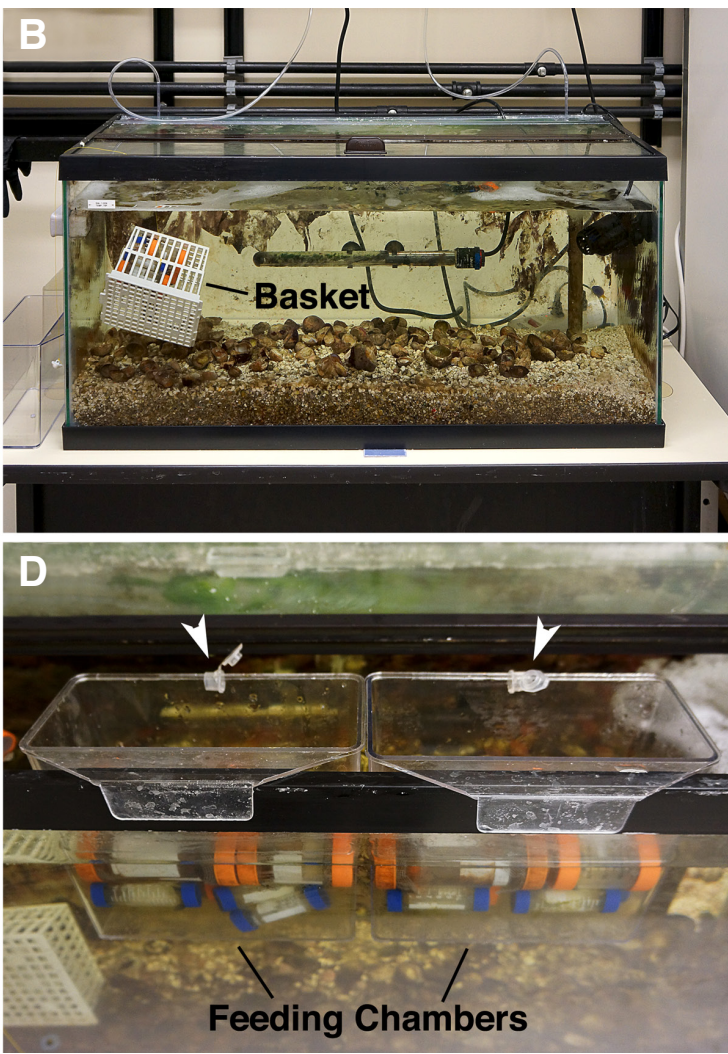

Fig. 2. Aquarium set-up and feeding chambers. (A) Recirculating marine aqaurium showing main components. Note air pump is located on a high shelf to prevent possible back siphoning of sea water into the pump should the power fail. (B) Tank set-up showing one orange-capped floating culture tube (top right) and submerged basket containing other various culture tubes (bottom left). Note large quantity of fine bubbles at the surface of the sea water. Empty C. fornicata shells are scattered over the substrate. (C) Close-up view of the submerged basket and culture tubes. Note yellow mono-filament fishing line is tied to the basket to permit retreval. (D) Two submerged feeding chambers are shown hanging from the front edge of the aquarium. Culture tubes

containing adult snails are seen inside these chambers. Normally the tank lid is closed during feeding to prevent loss of sea water due to spray and evaporation. To prevent these buoyant chambers from sealing tightly up against the closed glass lid, small plastic spacers (cut from the tops of $1.5 \mathrm{ml}$ eppendorf tubes, and indicated by white arrowheads) have been clipped to the back edge of the feeding chambers to provide space for air to circulate. 
ensure that the water temperature does not exceed this limit, the surrounding room must be maintained at a temperature lower than $27^{\circ} \mathrm{C}$ (typically around $20^{\circ} \mathrm{C}$ in our tank room). Water temperature should be checked routinely with a thermometer. Animals can be maintained at lower (room) temperatures though growth and development will proceed more slowly. Fluorescent overhead room lighting is sufficient. We maintain room lights on a timer with 12 hours of light during the day, alternating with 12 hours of darkness at night (lights on from 7am to 7pm).

Once the tank is set up and water is circulating through the filter bed it is time to inoculate the filter. To inoculate the filter bed we use Dr. Tim's Aquatics One and Only Live Nitrifying Bacteria for Salt Water Systems (Dr. Tim's, LLC, UPC code 12540 01200). One two ounce container is added to a 30 gallon tank. The bottle should be rinsed in the aquarium to ensure that all of the contents are added. Animals can be placed in the tanks after one week. Though the under gravel filter should provide adequate circulation and aeration, additional water circulation can be achieved using a small submerged circulating pump, such as an Aquatop CPS-1 (UPC code 19603 01479, Aquatop, Inc., Brea, CA). However, we have found that too much water flow may be harmful for juvenile snails.

Over time, water volume will gradually be lost due to evaporation and spray, and as such, it is important to closely monitor and maintain the water volume and salinity. Usually, one needs to add conditioned de-ionized (DI) or reverse osmosis (RO) water to decrease elevated salinity. Occasionally one may also need to add concentrated sea salts dissolved in DI/RO if the salinity should drop. If the water volume is too low then the flow of water through the airlifts can be impeded. Likewise, the water should not be so high that it covers the openings of the airlifts. The bottom of the openings of the airlifts should be about $1 / 2$ to 1 inch above the top level of the water in the tank to ensure good circulation and aeration (Fig. 2A). We have never needed to do complete water changes in the systems we maintain; however, if there should be serious problems and many animals should die, one will need to re-establish a fresh aquarium system. Algae will eventually grow on the glass walls of the tank. The algae is not harmful to the snails, but it is useful to have a Magfloat aquarium cleaner in the tank to periodically remove algae from the front glass (medium size, product number Float 125, UPC code 90950 00125, Gulf Stream Tropical Aquarium, Dania Beach, FL). Relatively little maintenance is required once the tank is set up. It is possible to do other water quality checks, such as for ammonia, nitrate, nitrite, alkalinity, etc., but we have not found this to be necessary. The main consideration is to maintain the conditions described above, and not overload the system with too many animals, or add too much food, in order to avoid toxic ammonia, nitrate and nitrite overload.

One should avoid putting their bare hands and arms in the sea water as much as possible. Soaps, perfume and lotions can be transferred to the sea water and are extremely toxic to the snails. Avoid using lotions and perfume, and wash hands and arms thoroughly before placing them in the tank. As an alternative, a small plastic aquarium net is very handy for retrieving items from the tank.

\section{Procuring the animals}

C. atrasolea is found in the low intertidal up to $20 \mathrm{~m}$ in depth in Southern waters of the Eastern Atlantic coast of the United States of America, from as far north as Core Sound, North Carolina down to the waters surrounding the tip of Florida, which includes those on the western side of the Gulf of Mexico (Collin, 2000a, 2001, see http:// www.sms.si.edu/irlspec/Crepid_atrasol.htm). We have collected adults from the waters near the Smithsonian Marine Station at Fort Pierce, FL (at the base of the Smithsonian dock located adjacent to the Harbor Island Condominium complex, Fort Pierce, FL-GPS latitude 27.456342775215486; longitude -80.30973136425018) in February 2015 and March 2016. The adults can be found attached to various natural or manmade hard substrates in shallow waters along the shore (see film prepared by Rachel Collin, https://www. youtube.com/watch?v=Ta16ztu85RU). Permission is required from the station to undertake collection at that locale. Like other slipper snails, the adult shells are flattened and not highly coiled. The shells are white. The animals have no operculum and must be attached to hard substrates. They do not form large curved stacks of snails like C. fornicata (Henry et al., 2010a). Males are smaller than females and range from 2-8mm in length (Fig. 1A). Females typically range from $5-16 \mathrm{~mm}$ in length. Superficially, these snails are hard to distinguish from other white-shelled Crepidula species found in those waters, including $C$. depressa and $C$. plana. However, the foot (as well as other parts of the body) contains a distinctive sooty black pigmentation (note that while this pigment may be observed in all wild caught specimens, we have found that this is harder to spot in some juvenile animals reared in the lab). This feature is the distinguishing characteristic from which the species name, atrasolea, meaning "black foot", is derived (Fig. 1 B-D). That pigmentation, along with their large egg size and their characteristic mode of direct development, distinguishes these snails from $C$. depressa and $C$. plana. Other distinctive characteristics include the development of the protoconch, and the anatomy of the radula, the penis, and the female genital papilla (see Collin, 2000a; Fig. 1 B-C).

As their shells are thin and the columellar muscle is small (Collin, 2000a) one must be very careful when detaching the animals from their substrates to avoid detaching the fragile adults from their shells. Animals can be dislodged from their substrates using a thin flat laboratory metal spatula. The spatula can be inserted under the thicker apex and then the foot to break the surface tension before trying to lift them. If at all possible, it is best to leave the animals on those substrates until they are brought to the lab. As described, these animals do not have an operculum for protection and need to be attached to a hard substrate, which is also critical for efficient water circulation, aeration and filter feeding (Fig. $1 \mathrm{~B}-\mathrm{C}$, E). Detached animals must be placed quickly onto a hard substrate such as a shell or a small piece of Plexiglas, or inside of a plastic culture tube (described below, Fig. 3). Animals that cannot attach to a substrate will perish. Special procedures are detailed below for lifting smaller snails (see below).

\section{Shipping / transport / acclimation}

Once collected, the animals can be shipped overnight submerged in fresh seawater contained in sealed doubled plastic bags packed in a Styrofoam container containing a few freezer packs to keep them from getting too hot (be careful not to over chill the animals). Sturdy thick plastic bags, closed with plastic zip ties, should be used as the substrates on which they are attached may have sharp projections that can cause leaks during shipping. Alternately, adult and juvenile snails can be shipped in plastic bags or small sealed tubes containing paper towels moistened with sea water. 
Once received, the animals should be acclimated to their new environmentfollowing standard procedures. Briefly, the plastic bags containing the snails should be floated in the seawater aquarium so that the temperature can become equilibrated. This may take 30 minutes or more depending on the volume of seawater in the bags. Bags should also be opened immediately so that they can receive fresh air. Take care to prevent the bags from sinking, which would allow the water to mix prematurely. Tank sea water should then be slowly introduced into the bag over a period of about one hour so that the salinity can be matched to that of their new environment. Once this is accomplished, the snails can be introduced into the aquarium. The adults are typically sedentary and larger females are not likely to move from their substrates, however they can wander. It is best to place the animals with their substrates into slotted plastic containers, such as a Lee's 2-way slotted breeder (Lee's Aquarium and Pet Products, product number 10250, UPC code 10838 10250, San Marcos, CA) to prevent the snails from crawling away. The lids can be secured using plastic zip ties, as needed. However, we prefer to remove the animals from their substrates and transfer them to plastic culture tubes (see below). Animals can be maintained for at least two years in captivity. The upper time limit has not yet been determined.

\section{Construction of culture chambers}

Screened culture chambers are constructed from either $50 \mathrm{ml}$ or $15 \mathrm{ml}$ screw top polypropylene tubes (Corning \# 430897 (50ml) and Nunc \# 339651 (15ml) Corning Inc., Corning, NY; and Nalgene Nunc, Rochester, NY, respectively, Fig. $3 \mathrm{~A}-\mathrm{H}$ ). The bottoms of the tubes are cut off square using a hack saw or a band saw (Fig. 3B) at the $40 \mathrm{ml}$ mark (for the $50 \mathrm{ml}$ tubes) or the $11 \mathrm{ml}$ mark (for the $15 \mathrm{ml}$ tubes) and discarded. The top portion and the screw cap are saved to prepare the culture chambers. Two tubes are needed to complete each chamber. The size of the chambers can be adjusted, as needed, by the length of the cut tubes. Shorter chambers are preferable, as longer chambers tend to reduce water flow and make it harder to feed the animals (see below). The cut edge must be perpendicular with the long axis of the tube and made completely flat. A power sander, sandpaper and a razor blade are used to clean up the cut edge, and to remove any burrs (Fig. 3C). The two ends of the tubes must match perfectly with no gaps so that snails cannot escape. The closed ends of the screw caps themselves are removed by carefully sawing these off to open up the caps (Fig. $3 \mathrm{E})$. The intact rim of these caps is saved to secure the fiberglass screen mesh. The screen is cut into squares approximately $2 \times 2$ inches for the larger chambers, (or $1 \times 1$ inch for the smaller ones) and the four corners can be trimmed so that they do not protrude once the mesh is affixed to the chambers (Fig. 3F). Standard fiberglass window screen has a mesh containing 18 strands per inch in one direction and 16 strands per inch in the other (Phifer, Inc., Tuscaloosa, Alabama). Avoid use of mesh with finer openings, such as finer grades of Nitex, as water and food will not pass through those freely. As an alternative, we use 20 × 20 "No-See-Um" mesh (Phifer, Inc., product number 3032230, Tuscaloosa, Alabama), which has a finer mesh containing 20 strands per inch in each direction. However, once the animals are large enough to ensure they cannot escape, the larger mesh should be used. Do not use metal mesh, which will become corroded. The two halves of the chambers are held together using a sleeve prepared from the left-over body of one $50 \mathrm{ml}$ or $15 \mathrm{ml}$ screw-top tube which is slotted along its length (Fig. 3C, G-H). The construction of these chambers allows for easy access to the animals, as one can approach them from both ends, as well as from the middle. Culture tubes should be marked with permanent labels using a metal scribe so that they can be identified. Animals should be transferred to the culture chambers once they are large enough that they cannot escape through the openings in the screens (for timing, see Overview of Early Development, below).

One can allow these culture tubes to simply float at the surface of the sea water, as they are positively buoyant and will lie just under the water's surface. However, culture tubes left to float freely in the tanks can accumulate along one side of the aquarium, limiting water flow through the tubes. Air bubbles may also accumulate inside the
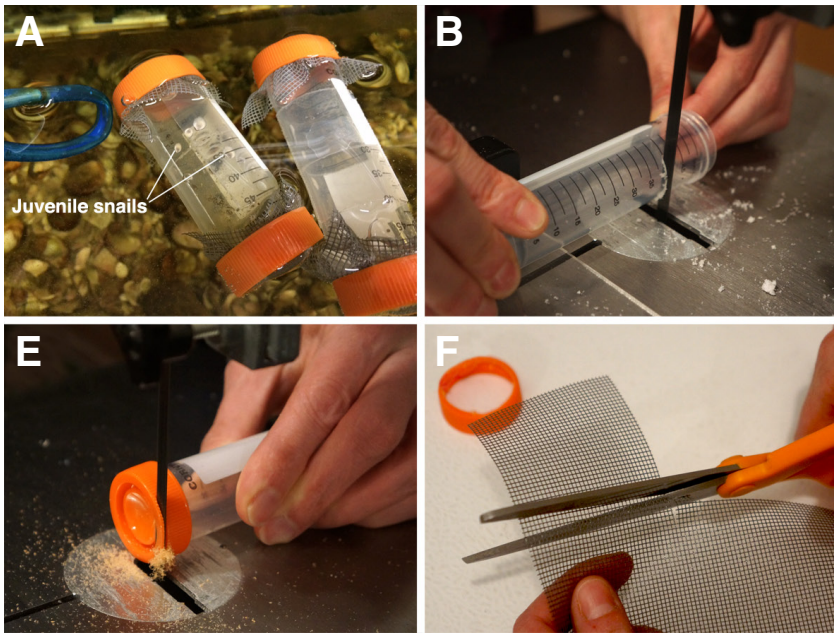
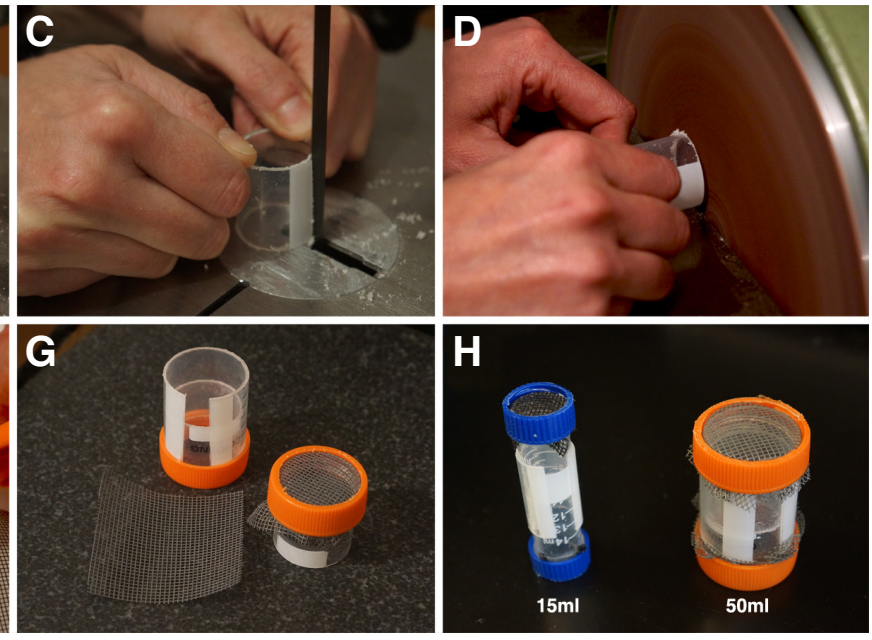

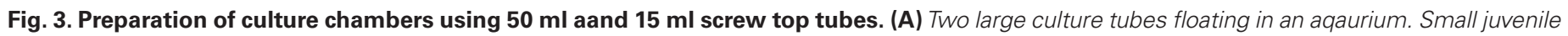

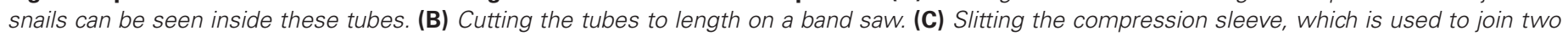

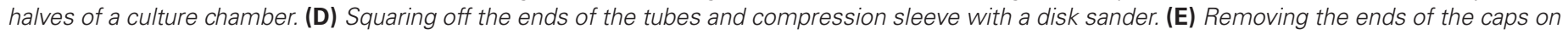

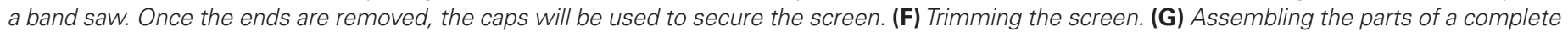

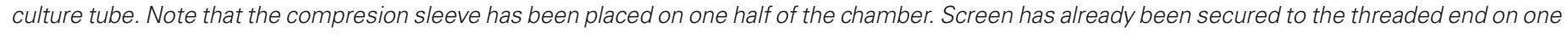

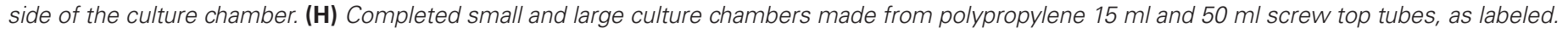


tubes, which can expose the snails. Though this does not appear to be a significant problem, one can ensure that the ends remain unblocked by using a submerged rack or basket. This helps keep the tubes organized, making it easier to find specific cultures. One solution we have used is to secure and submerge the tubes using small lab dishwashing baskets with hinged, locking lids (Nalgene polypropylene basket, product number 69170127, ThermoFisher Scientific, Waltham, MA, Fig. 2C). A length of nylon fishing line is tied to the rack to simplify its retrieval from the tank. Dead animals should be removed from the culture chambers as soon as they are found.

\section{Feeding the adults}

Adults are primarily sedentary and feed by suspension filter feeding, though younger animals and small males can also feed by grazing. The animals should be fed daily, though we routinely skip feeding one day each week. Feeding is accomplished using static containers that are hung inside the aquaria (Fig. 2D). Lee's Aquarium and Pet Products provides these in two sizes (large and small specimen containers, product numbers 10524 and 10515, respectively, UPC code 1083810524 and 10838 10515, San Marcos, CA). We feed animals once each day, overnight. The animals can be reared on live cultures of marine phytoplankton. Culturing phytoplankton is a laborious process and we have found that commercial preparations work very well. We have tested two commonly used products: DTs Live Marine Phytoplankton (Sycamore, IL) and Phytofeast (Reef Nutrition, Reed Mariculture, Inc. Campbell, CA, UPC code 51967 00113). Both of these can be purchased through local pet shops. DTs contains three different algae, Nanochloropsis oculata, Nanochloropsis salina and Chlorella sp. (4gm of biomass per liter). Phytofeast is a much more concentrated preparation with $93 \mathrm{gm}$. of biomass per liter (we counted the number of cells at $1.5 \times 10^{9}$ cells per $\mathrm{ml}$ in the stock). Phytofeast contains a blend of six different species (Pavlova, Isochrysis, Thalassiosira weissflogii, Tetraselmis, Nannochloropsis, and Synechococcus). One published study claims that DT's is better at supporting growth of juvenile Mercenaria clams compared to several other commercial preparations and individual mono-specific cultured preparations (Espinosa and Allam, 2006). These products have a limited shelf life and must be refrigerated $\left(4^{\circ} \mathrm{C}\right)$. DT's and Phytofeast typically last up to four months in the refrigerator, which is specified by the expiration data printed on the bottles. We prefer to use Phytofeast as a more cost effective solution due to its higher algal concentration. For feeding, the large specimen containers are filled with 500 $\mathrm{ml}$ of sea water directly from the aquarium. A permanent mark can be scribed on the container to indicate the water level for ease and future reference. Several of these tanks can be suspended inside the front of the aquarium as needed, depending on the number of culture tubes that need to be fed. $900 \mu$ of suspended Phytofeast is added to $500 \mathrm{ml}$ of sea water in each of those containers and the water is thoroughly mixed to disperse the phytoplankton (for a working concentration of $2.7 \times 10^{6} \mathrm{cells} / \mathrm{ml}$ ). The culture tubes are then placed into the container to ensure removal of any air bubbles in the tubes. Each container can hold four to six large culture tubes (or two to four in the smaller containers). Many more of the smaller culture chambers can be put in these feeding containers. Animals are allowed to feed overnight or throughout the day, but not left longer than 15 hours in these static feeding containers.
After feeding, the tubes and the contents of the feeding containers are returned to the aquarium. Any settled phytoplankton should be removed from the feeding containers by rinsing them under the tap and wiping them clean and allowing then to air dry after each use. Food can transit through the digestive tract very quickly, and may be ingested continuously. For a juvenile snail approximately $1-2 \mathrm{~mm}$ in length it takes approximately 10 minutes for ingested food to first be excreted. Freshly ingested food is excreted as numerous small uniform, oblong feces. Reports indicate that animals reject excess food when it is present at high concentrations (as "pseudofaeces", see Chaparro et al., 2002, 2004; Shumway et al., 2014). It is important to remove accumulated fecal material inside the culture chambers by dunking and draining them a few times in the main aquaria, as they are returned after each feeding. This allows the feces to pass directly thru the screens and into the main tank. Alternatively, one can pull the tubes apart to flush out larger debris. Over time, biofilm and algae will accumulate and block the screens covering the ends of the culture chambers; thus, these should be periodically wiped clean using a Kimwipe. If a thick biofilm forms inside the culture tubes, they can also be carefully wiped clean, or the animals can be transferred to clean tubes.

\section{Collecting and rearing the eggs and embryos}

All Crepidula snails brood their embryos (Fig. 1D). One can observe animals daily for any freshly laid eggs, as these can be observed and staged through the transparent walls of the culture chambers. To recover eggs and embryos you need to lift the adults from their substrates. To do this (especially for the smaller animals) we use a dull, fine sewing needle mounted in a sturdy handle (Fig. $4 \mathrm{~A}-\mathrm{H})$. The needle works better to prevent damage to the shell compared to a fine metal spatula or a pair of forceps. A wooden dowel or a short glass Pasteur pipette works well as a handle (Fig. 4 A-D). The end of the needle containing the eye can be affixed inside the end of the pipette using UV polymerizing plastic, such as Bondic (Laser Bonding Tech, Inc., Aurora, ON, Canada, Fig. 4D). Alternatively, a small hole can be drilled in the end of a wooden dowel to affix the needle. The sharp needle tip needs to be rounded so that it does not damage the soft tissue of the foot when pushed under the shell. It can be blunted slightly using a wet stone or a diamond fish-hook sharpener (EZE-Lap Pocket Diamond Fish hook sharpener, EZ-S model S, Carson City, Nevada, Fig. 4B). The end is then burnished to a smooth ball shape by pushing and spinning it inside one corner of the recessed lettering, which is present on each set of Dumont no. 5 watchmakers forceps (Fig. 4C). Alternatively, you can rub the tip on a smooth metal surface. To lift an animal, the needle is first inserted under the thicker (and much stronger) apex of the shell and then further under the foot to break the surface tension (Fig. 4 E-G). One must proceed slowly. Do not attempt to push the needle under the thinner edges of the shell, as those are very fragile. It helps to be able to see the foot, as you accomplish this, so animals should ideally be attached to transparent substrates such as those of the culture tubes (Fig. 4 F-G). Great care must also be taken not to try to lift the animal by the shell only, as this may rip the soft tissues from the shell and the animal will die. Once the seal of the foot is broken, the animal can be readily pried from the substrate. We perform this operation in the open air, as it is harder to manipulate the animals raised in culture tubes when they are submerged. The egg sacs, which are 
usually attached to the substrate, can then be recovered cleanly using watch maker's forceps and transferred to a small $35 \mathrm{~mm}$ petri dish containing Pen-Strep filtered sea water (Fig. 4H, PSFSW, see next paragraph). So as not to crush the embryos, it is best to grab the egg sacs by their fine attachment threads, though these are hard to see under these conditions when they are not submerged (Fig. 1E). With animals collected from the wild and attached to shells or other hard substrates, it will not be possible to monitor the foot as animals are being lifted. You may also have to use a more substantial implement to pry off these larger animals, such as a small spatula, as mentioned above. Proceed slowly and with great care so as not to damage the animals. The animals' shells grow to fit the contour of the substrate precisely, and so they should be returned immediately to the exact same locations and in the same orientation on those substrates or in their culture tubes, and placed back to the sea water quickly to prevent desiccation. One must monitor the animals to make sure they stay on their substrates and return them if they should become detached. Unlike the tiny juvenile snails, large adults cannot flip themselves over to reattach to the substrate.

Artificial sea water is filtered (FSW) through $0.2 \mathrm{~mm}$ SFCA rapid filters into sterile bottles (Nalge Nunc International Rochester, NY, product number 291-4520), and the addition of antibiotics is essential for successful culture of these embryos. Penicillin sulfate (100units $/ \mathrm{ml})$ together with streptomycin $(200 \mu \mathrm{g} / \mathrm{ml})$ is added to the filtered sea water (PSFSW). Embryos are removed from the capsules using pairs of sharpened number 5 Dumont forceps. The capsules are very delicate and easily ripped open. Once removed from their capsules, the naked eggs and early stages will stick to the dishes (there is no vitelline envelope). However, once the embryos become ciliated and motile they are no longer sticky. To prevent eggs and early embryos from sticking, one must coat the petri dishes with gelatin or agarose. Gelatin is made up as a $5 x$ stock (this can be stored at room temperature for several months), consisting of $0.25 \mathrm{gm}, 0.5 \% \mathrm{Knox}$ unflavored gelatin (dissolve before adding formalin, Kraft Foods, Inc., USA) and $250 \mu$ l of a $37 \%$ stock formalin solution ( $0.19 \%$ formaldehyde final concentration) in $50 \mathrm{ml} \mathrm{dH_{2 }} 0$. For coating dishes, dilute to $1 \mathrm{x}$ working strength immediately before use with $\mathrm{dH}_{2} \mathrm{O}$. Pour several mls of solution into the $35 \mathrm{~mm}$ Petri dishes, swirl and pour off remaining solution into the next dish to be coated. A thin film will remain in each dish. Allow these dishes to air-dry completely by tipping them upside down. Transfer pipettes and operating needles can also be coated with this $1 x$ working solution. Loose early embryos will survive about seven days in gelatin coated dishes. Alternatively, one can use agarose coated dishes. $1 \%$ agarose is made up in FSW and dissolved by autoclaving. Use this solution to coat the bottom of the petri dishes. After the agarose has cooled and solidified, the plates must be kept in sealed bags and stored at $4^{\circ} \mathrm{C}$ until needed to prevent them from drying out. Younger embryos develop and survive better in agarose coated dishes. Dishes stored for long periods of time may dry out, which will increase the salinity of the agarose pad and possibly harm the embryos. If lids are used, it is important that the seawater not be allowed to contact the lid as this will reduce the air-water interface and oxygenation. This can be avoided by not overfilling the dishes with sea water.

\section{Overview of early development}

C. atrasolea eggs are approximately $335 \mu \mathrm{m}$ in diameter (Collin, 2000a) (Table 1, Fig. 5A). They are a pale yellow color and opaque, as they are filled with yolk. Occasionally, smaller eggs can be observed that also undergo development. The embryos develop into an intracapsular non-feeding veliger with a small reduced ciliated velum. C. atrasolea is essentially a direct developer forming crawl-away juveniles, similar to those described for $C$. convexa (Lyons et al., 2012) and some other species (e.g., C. adunca, Collin, 2000b). These embryos are not adelphophagic and there are no nutritive eggs present in the egg capsules (Collin, 2000a). Transient larval structures are formed but greatly reduced. Small ciliated velar lobes are formed as are the paired external larval absorptive cells (originally referred to as the "larval kidneys" by

Fig. 4. Preparation and use of a tool for lifting animals to recover their embryos. (A) Components needed to make the lifting tool, as labeled. (B) The fine sewing needle is gently blunted using a diamond fishhook sharpener usning the dissecting scope. (C) The blunted end is then burnished to a smooth ball using metal number 5 dumont forceps as described in the text. (D) The needle is cemented into the handle (a glass Pasteur pipette) using UV polymerizing plastic (e.g., Bondic). (E) The screw cap and screen have been removed from one end of a culture chamber to reveal male and female snails, as labeled. The large female is brooding embryos. (F) View from the opposite side through the wall of the culture that reveals the brooded embryos. To lift the snail, the fine needle is first inserted under the shell at the stronger apex. (G) The needled is slowly pushed in further under the shell and eventually under the foot to introduce air which will break the seal (surface tension). One must proceed very slowly, so as not to damage the snail. In addition, do not
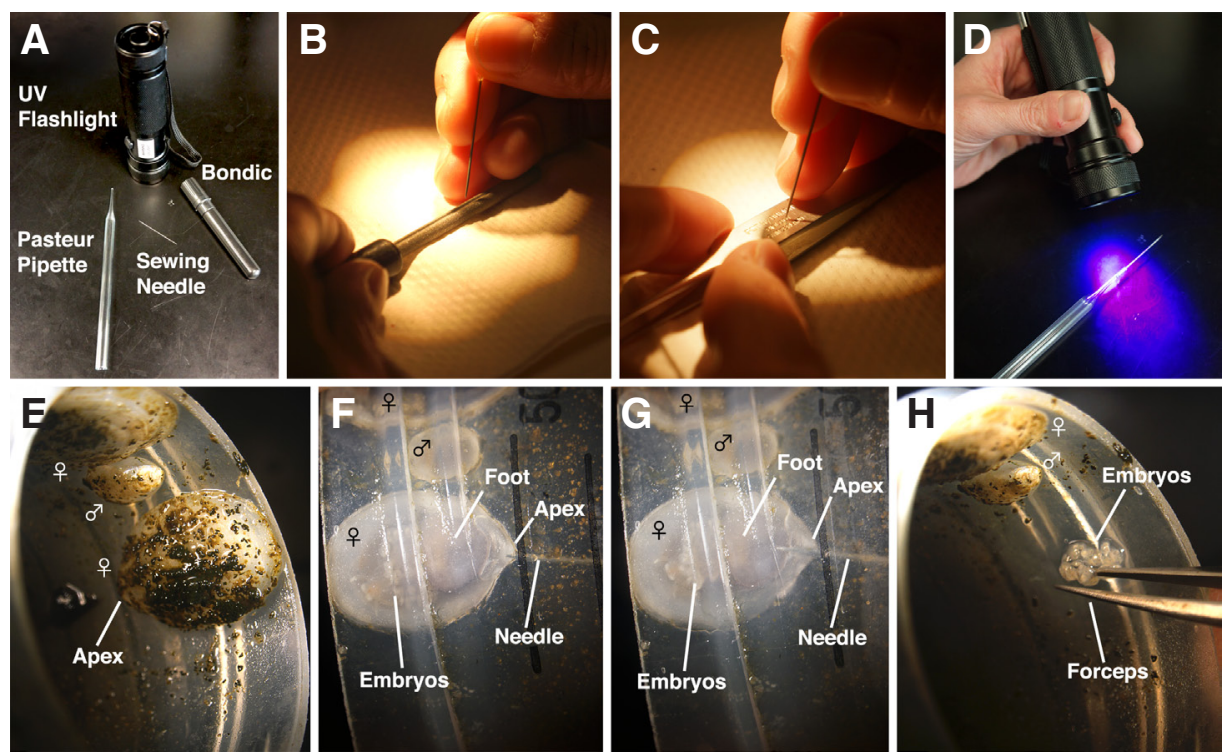

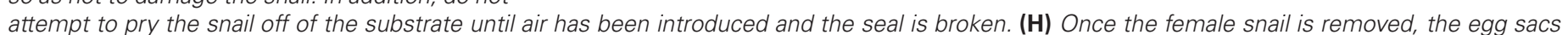
containing embryos, which are typically attached to the substrate, can be collected using watchmakers forceps. 
some authorities, Fig. $5 \mathrm{~K}-\mathrm{L}$ ), which are lost during metamorphosis in Ilyanassa obsoleta and C. fornicata (Lyons et al., 2012; Rivest, 1992). Unlike the situation encountered for $C$. fornicata, where an operculum is formed on the larval foot, but lost in the adult, no operculum is ever formed on the foot in $C$. atrasolea, similar to the situation encountered for $C$. convexa, and $C$. adunca (Collin, 2000b; Lyons et al., 2012).

In the lab, females lay from 8 to 20 egg capsules, each typically containing around 5 to 7 eggs (Fig. 1 D-E). Collin (2000a) reports that capsules contain around 20 eggs each in the wild. The smaller number of eggs produced in the lab may be related to the level of nutrition these animals are receiving (see below). Also, animals in the wild tend to be larger and have continuous access to food. Females will lay batches of eggs repeatedly throughout the year. Once she has laid a clutch, however, a female will not lay new eggs until the older ones have hatched. Females can lay fresh batches of eggs very quickly after their previous clutch has hatched. In fact, we have observed females to lay fresh eggs within 12-48 hours after her previous clutch has hatched or is removed. Females store sperm, thus isolated females can lay eggs weeks or even months after they are removed from their male partners.
Early cleavage divisions proceed at a pace very similar to that recorded for $C$. fornicata and $C$. convexa. At $25-27^{\circ} \mathrm{C}$ it takes approximately 6 hours to reach first cleavage (Table 3 and Fig. $5 \mathrm{~A}-\mathrm{C}$ ). A small polar lobe is formed before the first cleavage furrow appears (Fig. 5B). The polar lobe is approximately $20 \mu \mathrm{m}$ in diameter. The first cleavage furrow is initiated at the animal pole. First cleavage is essentially equal (Fig. $5 \mathrm{C}$ ). The polar lobe is resorbed before this division is completed, making it difficult to determine which cell inherits the polar lobe. The time between first and second cleavage and the interval between successive micromere quartets takes approximately four hours. A small second polar lobe forms at second cleavage, which can be observed to fuse with one of the four blastomeres. Subsequently, during early cleavage, two opposing macromeres are separated by a prominent vegetal cross-furrow. It takes 24-25 hours to reach the formation of the $4 \mathrm{~d}$ mesentoblast (Fig. 5D). Following this stage the embryos become rounded and compacted, as they undergo epiboly (42-116 hpf, Fig. 5E). The other fourth quartets are born at approximately 40-41 hpf (Fig. 5F). Gastrulation occurs by epiboly and spans between 42-116 hpf (Fig. 5G). The embryo then undergoes elongation (ovoid stages) between 119-164 hpf. This period
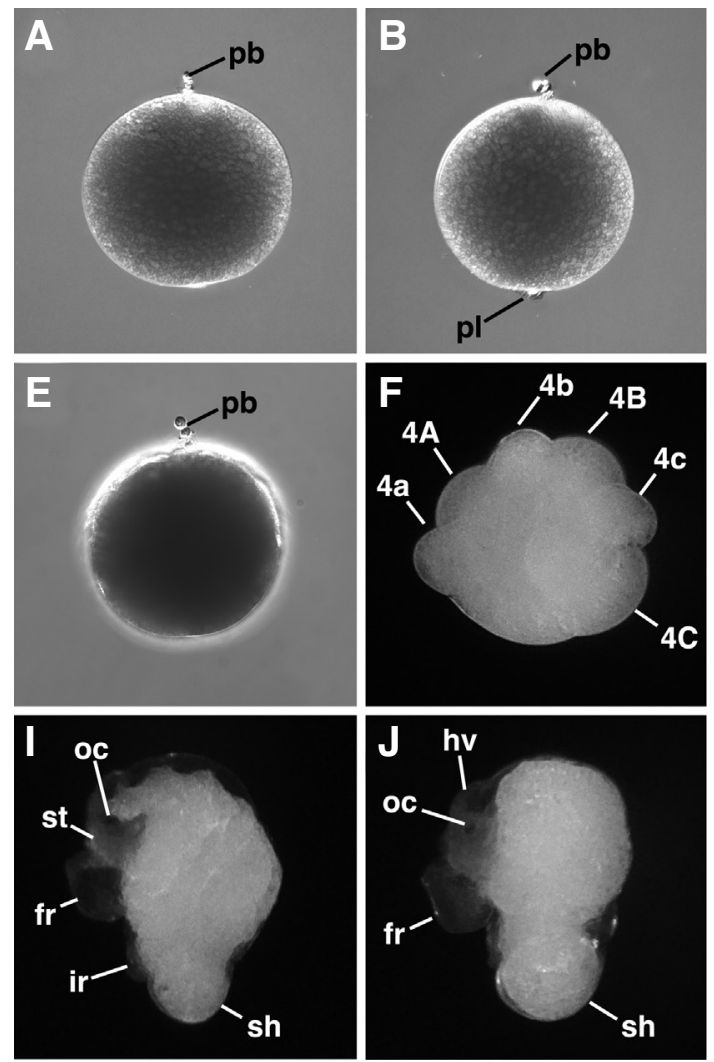
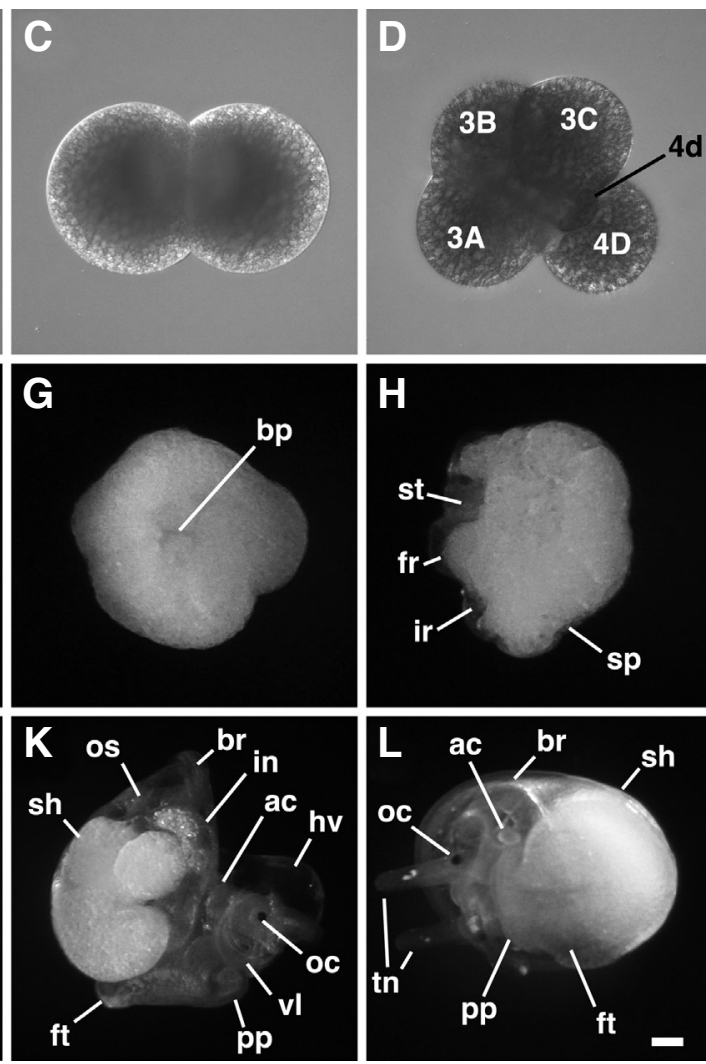

Fig. 5. Representative stages of C. atrasolea development. (A) Lateral view of a fertilized egg which has undergone meiotic reduction divisions to form animal polar bodies. (B) Small polar lobe forming at the vegetal pole prior to the first cleavage division. (C) Animal pole view of a two-cell stage embryo following the first division. Note that first cleavage appears to be equal. (D) Animal pole view of a 25-cell stage showing the precocious formation of the $4 d$ mesentoblast. As is the case in other species of Crepidula, this is a relatively large cell that extends to the center of the embryo. Note also the four large vegetal macromeres (3 A-C, 4D). One of these macromeres (4D) protrudes noticeably from the embryo. (E) Lateral view showing spherical, compacted stage of development seen just before and after the stage shown in F. Note that the thin animal cap of ectoderm is partially covering the yolk-rich vegetal macromeres. Polar bodies are located at the animal pole. (F) Late cleavage stage

showing formation of the other $4 q$ micromeres $(4 a, 4 b, 4 c)$ along with their corresponding sister macromeres $(4 A, 4 B, 4 C)$, as labeled. (G) Vegetal view during gastrulation showing irregular-shaped, flattened embryo with large blastopore. (H) Left lateral view of elongated stage of development showing beginning of overt organogenesis. (I) Lateral view of an even older embryo. Note protruding posterior region and pigmented ocelli are now present. (J) Left lateral view of an older case showing coiled shell covering the posterior region of the embryo. The head vesicle is begining to enlarge. The coiling shell can be seen to cover the posterior end of the embryo. (K) Left lateral view of an advanced stage showing the shell is now flattening and has a pronounced brim that surrounds the aperture. Note that at this stage the shell is initially tipped upward and does not cover the head. (L) Ventral view of a more advanced pre-hatching stage showing the flattened shell, which now covers the head. Structures are as labeled. See (Table 2) for further details regarding stages of development. Cells labeled in D and F follow the nomenclature of Conklin (1897). ac, absorptive cell; bp, blastopore; br, brim around shell aperture; fr, foot rudiment ft, foot; $h v$ head vesicle; in, intestine; ir, intestinal rudiment; oc, ocellus; os, osphradum; pb, polar bodies; pl, polar lobe; pp, propodium; sh, shell; sp, shell plate; st, stomodeum; th, tentacles; vl, velar lobe. Scale bar in (L) represents $50 \mu \mathrm{m}$. 
of development is followed by one of organogenesis in which many of the larval and juvenile rudiments become apparent (7-14 days) as described in Table 3 (Fig. $5 \mathrm{H}-\mathrm{J}$ ). One can observe the formation of vestigial velar lobes, the foot and the shell (Fig. $5 \mathrm{H}-\mathrm{L}$ ). The individuals hatch as crawling juveniles with flat shells after about 21-23 days of development (Fig. 1 E-F, 5L). Occasionally, a female will abandon her pre-hatching stage embryos. It is not clear if she eats them or they simply wash away. So as not to lose track of the hatchlings, which would become dispersed in the main aquaria, we recover the egg sacs a few days early (between 17 to 19 days of development), as soon as the shells have flattened and there is very little to no visible yolk inside these snails. These juveniles are artificially hatched into the plastic petri dishes using fine number 5 watchmakers forceps to rip open the sacs under PS FSW, as described above. If these juvenile snails are left in their sacs in these dishes, they may become trapped and will die.

Once the juveniles hatch, they will begin to crawl on the plastic surfaces of the petri dishes. Juveniles are highly motile and can strand themselves above the water line, if water levels are not topped up. Do not use lids on these dishes, as the water will wick to the tops preventing efficient aeration, and the snails will crawl upwards onto the lids. At this time, water changes are easily accomplished by simply pouring out the sea water. The snails will remain attached to the dishes. Snails can move to the air-water interface where they will raft on the surface. To avoid losing those snails, one must submerge them with fine forceps or a needle so that they can re-attach to the dish. We typically rear the snails for one month before they are big enough to be transferred to the culture tubes in the main aquarium. At this point the snails are 1.5 to $2 \mathrm{~mm}$ in length and too big to escape through the screen mesh. Juvenile hatchlings begin to develop a penis at a shell length of approximately $2 \mathrm{~mm}$, or around 8-10 weeks of age. Females' external genitalia begins to develop in some of these individuals by three to four months of age, however they will not become reproductive until they reach approximately $7-9 \mathrm{~mm}$ long, which can take up to 6 months in our lab. To date, we have reared snails through four successive generations. To keep track of individual snails one can mark their shells with characters or a pattern of dots using India ink and a fine pen (such as a 3x0 or finer Koh-I-Noor Rapidograph pen, Chartpak Inc, Leeds, MA, see Fig. 1F). The exposed surface of the shells must be dried before applying the ink.

\section{Feeding and cleaning juveniles}

Hatched, juvenile snails are also fed Phytofeast daily. Juvenile snails are initially raised in small $(35 \mathrm{~mm})$ petri dishes (approximately 20-40 snails per dish). We use uncovered $35 \mathrm{~mm}$ petri dishes containing approx. $5 \mathrm{ml}$ of FSW when filled to the brim. Instead, these petri dishes are placed inside a larger moisture chamber containing dampened Kimwipes or sponges to prevent evapora-

TABLE 3

\section{TIMING AND STAGES OF DEVELOPMENT IN C. ATRASOLEA}

\begin{tabular}{|c|c|c|c|}
\hline Process & Description/Landmarks (Stage) & Age (pf) & Examples \\
\hline \multirow[t]{4}{*}{ Early Cleavage } & Formation of the four micromere quartets & $0-41 \mathrm{hr}$ & \\
\hline & $\begin{array}{l}\text { Zygote to 24-cell stage } \\
\text { Formation of the first three micromere quartets }\end{array}$ & $0-23 \mathrm{hr}$ & Fig. 5A-C \\
\hline & $\begin{array}{l}25-\text { cell stage } \\
\text { Formation of } 4 d\end{array}$ & $24-25 \mathrm{hr}$ & Fig. 5D \\
\hline & $\begin{array}{l}\text { Fourth quartet formation } \\
\text { Formation of } 4 \mathrm{a}-4 \mathrm{c}\end{array}$ & $40-41 \mathrm{hr}$ & Fig. $5 \mathrm{~F}$ \\
\hline \multirow[t]{4}{*}{$\begin{array}{l}\text { Epiboly } \\
\text { (Gastrulation) }\end{array}$} & $\begin{array}{l}\text { Compaction and coverage of macromeres by the animal } \\
\text { cap micromeres }\end{array}$ & 42-116hr & \\
\hline & $\begin{array}{l}\text { Round stage } \\
\text { Compaction occurs }\end{array}$ & $42 \mathrm{hr}$ & Fig. 5E \\
\hline & $\begin{array}{l}\text { Epiboly, Round Stages } \\
\text { Macromeres divide causing flattened irregular shapes }\end{array}$ & $43-116 \mathrm{hr}$ & Fig. 5E \\
\hline & $\begin{array}{l}\text { Square or Rectangular stage } \\
\text { Assumes rectangular shape }\end{array}$ & $117-118 \mathrm{hr}$ & Fig. 5G \\
\hline \multirow[t]{3}{*}{ Axial Elongation } & Elongation occurs along the anterior-posterior axis & $119-164 \mathrm{hr}$ & \\
\hline & $\begin{array}{l}\text { Short or Early Ovoid stage } \\
\text { Ciliated cells present ventrally and posterior to stomodeum }\end{array}$ & $119-131 \mathrm{hr}$ & \\
\hline & $\begin{array}{l}\text { Long or Late Ovoid stage } \\
\text { Small, oval mouth displaced anteriorly, Shell gland visible }\end{array}$ & $132-164 \mathrm{hr}$ & \\
\hline \multirow[t]{6}{*}{ Organogenesis } & Appearance of external morphological rudiments & 7 days -14 days & \\
\hline & $\begin{array}{l}\text { Early Organogenesis } \\
\text { Shell plate forms, foot rudiment appears, absorptive cells present }\end{array}$ & 7 days & Fig. $5 \mathrm{H}$ \\
\hline & $\begin{array}{l}\text { Mid-Organogenesis } \\
\text { Posterior protrusion with shell having pronounced curvature and tilt to the left, head vesicle and apical organ forms, } \\
\text { vestigial velar lobes and prototroch cilia appear, pigmented ocelli, statocysts, and juvenile foot rudiment forms }\end{array}$ & $8-10$ days & Fig. 5I \\
\hline & $\begin{array}{l}\text { Late Organogenesis } \\
\text { Shell has a pronounced convex dorsal curvature and tilted to the left, tentacle buds seen, beating heart seen }\end{array}$ & 11 days & Fig $5 \mathrm{~J}$ \\
\hline & Brim first appears on edge of shell aperture, shell begins to flatten, shell tilted upwards and head is still exposed & 12 days & Fig. $5 \mathrm{~K}$ \\
\hline & Shell begins to flatten and shell comes down to cover head & 13-14 days & Fig. 5L \\
\hline \multirow{4}{*}{$\begin{array}{l}\text { Formation of the } \\
\text { Juvenile and Hatching }\end{array}$} & Growth and elaboration of the shell and foot & 15 days-3 weeks+ & \\
\hline & $\begin{array}{l}\text { Flattened shell becomes larger, ocelli move closer to the base of the tentacles, the foot becomes larger and more } \\
\text { elaborate with a well-developed propodium, gills develop }\end{array}$ & 15-17 days & Fig. 5L, Fig. 1E \\
\hline & $\begin{array}{l}\text { Yolk reserves are no longer visible in the digestive tract, snails are able to feed and survive on their own if removed } \\
\text { from the capsule }\end{array}$ & 18-20 days & \\
\hline & $\begin{array}{l}\text { Hatching } \\
\text { Juvenile snail hatches }\end{array}$ & $21-23$ days & Fig. 1F \\
\hline
\end{tabular}

The bolded headings list the principle phases of development, while terms used to describe specific sub-stages are in italics. 
tion. Water is exchanged once each day and snails are fed during or immediately following the sea water change. Prior to feeding, the old water is poured off, and replaced with fresh sea water. $7-10 \mu$ l of concentrated phytoplankton solution is added to each dish (final concentration of $3 \times 10^{6}$ cells per $\mathrm{ml}$ ). If the animals are younger or there are very few animals in each dish (1-10) a smaller amount may be added $\left(2.1 \times 10^{6}\right.$ cells per $\left.\mathrm{ml}\right)$. Immediately after adding the food it should be thoroughly suspended by trituration or stirring. With larger numbers of cultures, it is more convenient to make up larger quantities of sea water with suspended food to pour into those dishes. Food is left in the water until the next water exchange is accomplished. Generally, antibiotics are not needed after the animals hatch and this helps limit fungal growth (see below). Each day, for cases in which there is no fungal contamination (see below), and prior to exchanging the sea water, the animals are simply swept clean of any excrement (while still underwater) using a very fine, number 0 or smaller, natural bristle paint brush. Any debris that has accumulated on the bottom of the dish is also dislodged using the brush. The brush should be washed and rinsed with $70 \%$ ethanol after use.

\section{Treating infections}

Embryos initially need to be raised in the presence of antibiotics, otherwise these cultures will be over-run with bacteria. Antibiotics should be used until hatching occurs, and up to one week after hatching, if needed. After this time antibiotics are generally not required. After feeding begins, a fine white filamentous fungus may grow in the dishes and on the snails. Overcrowding, overfeeding and the use of antibiotics favor fungal growth. If fungus is allowed to accumulate on the shells, it will eventually prevent the animals from feeding, so the fungus must be removed. Many antifungal agents are toxic to marine invertebrates, such as those containing copper or malachite green. Other antifungal agents have been tested, which are not toxic to the snails for short durations, but none have been found to be effective in removing these fungal infections (including Amphotericin B (Fungizone), 5-Fluctyosine, Anidulafungin, Caspofungin, Fluconazole, Itraconazole, Micafungin, Posaconazole, and Voriconazole). Only Methylene Blue has been found to be somewhat effective in inhibiting fungal growth $(8 \mathrm{mg} / \mathrm{L}$ final), however long term exposure over five days to methylene blue will harm the animals. Animals should be treated for only 24-48 hours. Alternatively, fungus can simply be wiped off of the shells and the surfaces of the petri dishes using dry Kimwipes (Kimberly-Clark Worldwide, Inc., Rosewell, GA). Before wiping, the water should first be removed from the petri dishes. A gentle touch is required when wiping the shells with Kimwipes. Once fungus is established this procedure will need to be repeated daily. Generally, however, we do not encounter problems with fungal growth when the cultures are not over-crowded, not over-fed and antibiotics are omitted after the snails hatch. Additionally, fungal infections have not been noted as a problem for snails once they are transferred to the main aquaria.

\section{Future improvements for rearing $C$. atrasolea}

These culture procedures have proven to be very successful in our lab; however, there is always room for further improvements. In the wild these animals have nearly continuous access to food, so our lab conditions are likely to be sub-optimal in that regard. With our current feeding protocol, the food eventually settles to the bottom of the static feeding containers. Hence, animals may only have access to the food for 2-3 hours each day. A mechanism to agitate and re-suspend the phytoplankton could ensure for a longer feeding time and faster growth. One could also attempt to automate the feeding process, so that food can be introduced several times during the day. It may, in fact, be possible to introduce smaller quantities of food directly into the main aquarium for feeding throughout the day, with no need for separate feeding chambers. These conditions should shorten the time to sexual maturity. Juvenile growth rates can be increased by rearing the snails at lower densities, and we have been successful rearing juveniles in 24-well culture plates ( 1 individual per $3 \mathrm{ml}$ of sea water). There is also a need for safe, and more effective antifungal agents for the younger cultures.

\section{Genomic resources}

Increased accessibility and reduced costs of high throughput sequencing has increased the availability of genomic resources available for certain Crepidula species (see Table 2). To accelerate the use of $C$. atrasolea as a developmental model, we have produced an RNASeq assembly of the developmental transcriptome (see below). Additionally, the genome of $C$. atrasolea is currently being sequenced, and should be made available in the near future (estimated size is 3.2 to 3.8 gigabases). This will open up an array of functional assays and the ability to generate transgenic lines of these snails for future studies using approaches such as CRISPR/ Cas9 (Perry and Henry, 2015).

\section{C. atrasolea developmental transcriptome: RNASeq}

Total RNA was collected from 92-121 embryos collected at each of the following stages: 1) 2- cell to 25 -cell, early cleavage-stage embryos, 2) later cleavage-stage embryos including the formation the $4 \mathrm{a}-4 \mathrm{c}$ micromeres, 3) a mix of more advanced cleavage stages undergoing compaction and initiating gastrulation, 4) round (early gastrula) stage embryos, 5) flattened mid to late gastrula stages undergoing epiboly, 6) embryos undergoing elongation, 7) embryos initiating organogenesis, and 8) more advanced embryos with curved shells. RNA was extracted using Trizol, following the manufacturer's instructions (Invitrogen, Carlsbad, CA). Note that 100 early cleavage-gastrula stage embryos yields approximately $1.3 \mu \mathrm{g}$ of total RNA. 125ng of total RNA was removed from each sample mentioned above and pooled (to yield $1 \mu \mathrm{g}$ total RNA), as the starting material to prepare a single RNASeq library. The library was prepared using the TruSeq Stranded mRNA Sample Prep kit (Illumina, San Diego, CA), as per the manufacturer's instructions, with the following modification: fragmentation at $94^{\circ} \mathrm{C}$ for 1 minute. Fragment sizes were between $80 \mathrm{bp}$ to $900 \mathrm{bp}$, with an average size of $500 \mathrm{bp}$. Paired end, stranded reads were sequenced on a single Illumina HiSeq 2500 lane producing reads of 250nt in length using TruSeq Rapid RBS reagents (v2). Library preparation and sequencing was done at the Roy J. Carter Biotechnology Center at the University of Illinois (Urbana, IL).

Reads were assembled using default parameters of TrinityRNASeq (v2.2.0) (Grabherr et al., 2011). Assemblies and downstream analyses were run on the High Performance Computing Biocluster 
A

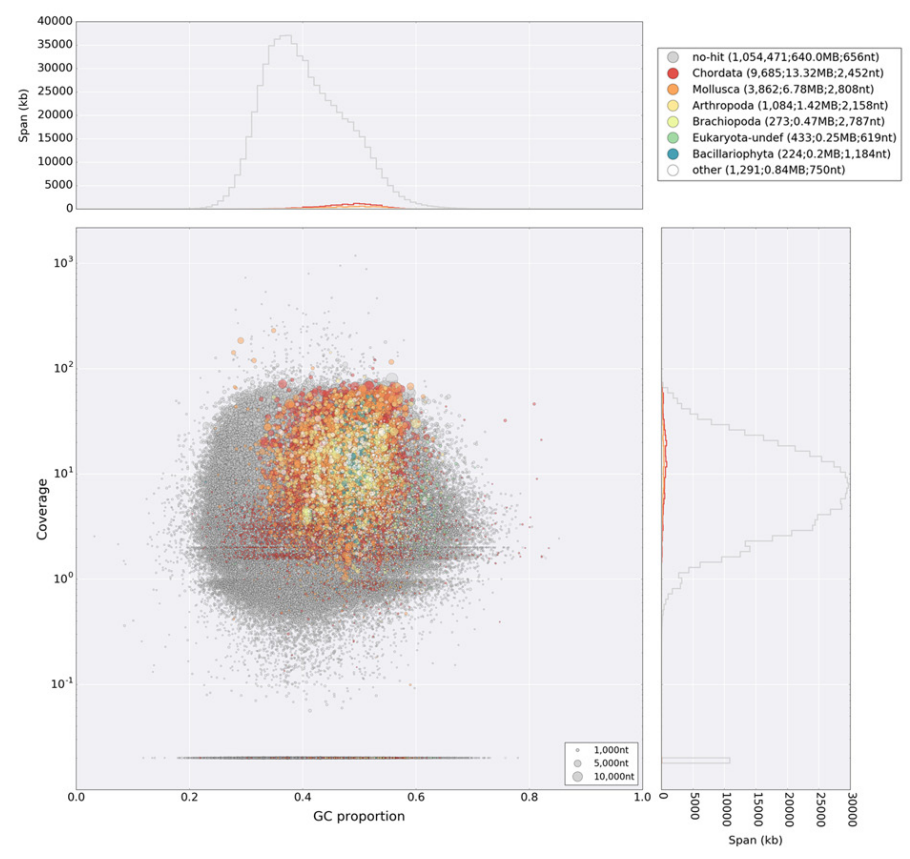

B

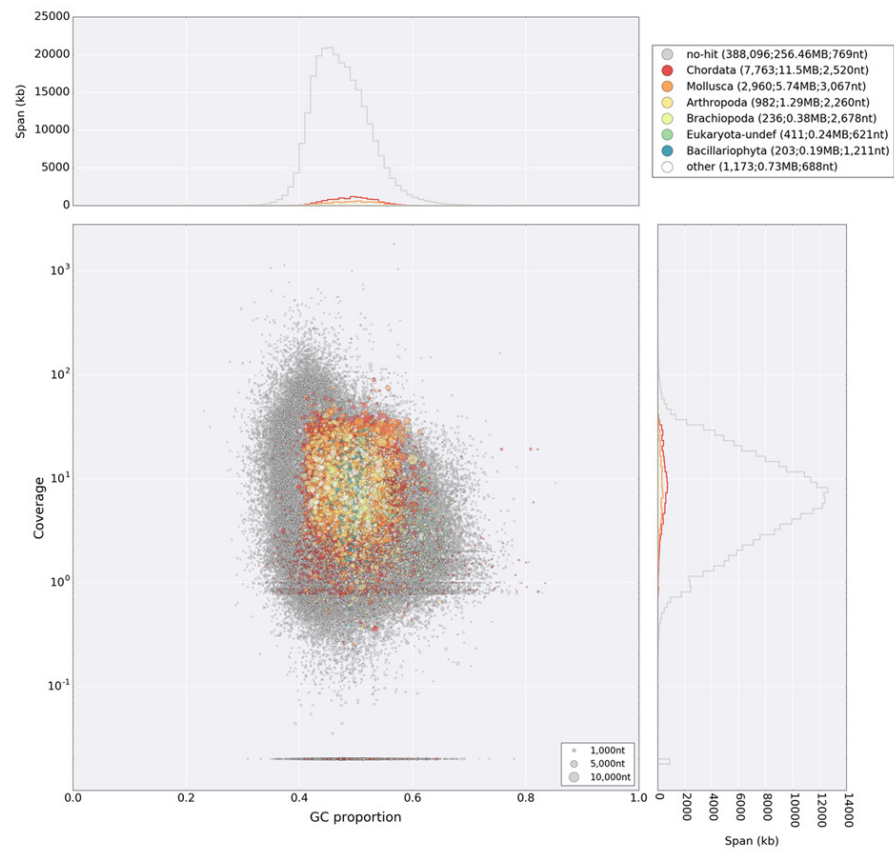

Fig. 6. Blobplots of developmental transcriptome assemblies of $\boldsymbol{C}$. atrasolea. Percentage GC content of assembled contigs is compared with depth of coverage (number of reads), indexed by BLAST taxon-ID (see key). Although coverage depth is a less useful metric for transcriptome data, this allows for visualization of potential contamination. Size of blobs represents number of nucleotides within a given cluster (see key), while colors represent the consensus of taxon-IDs based on BLAST sequence similarities (see key). Span represents sizes in basepairs. (A) Filtered assembly. (B) MCSC-pipeline cleaned assembly. No obvious contamination is noted based on these analyses. See text for further information.

at the Institute for Genomic Biology at the University of Illinois (Urbana, IL). Raw reads were trimmed, filtered for quality control and normalized using Trimmomatic and Trinity-based normalization using the default settings (Bolger et al., 2014; Haas et al., 2013). Cleaned reads were first assembled using default parameters of TrinityRNAseq and a kmer size of 25 bases. The initial assembly produced over 2 million 'transcripts', with an average contig length of 443.56 bases (Table 4). A second assembly using a kmer size of 31 bases was also produced using Trinity (Table 4). The larger kmer size resulted in a slightly improved assembly, based on reference-free scores calculated with Transrate (v1.0.3) (SmithUnna et al., 2016), Detonate (Li et al., 2014), BUSCO (v2) scores (Simão et al., 2015), and alignment based read mapping using Bowtie2 (Langmead and Salzberg, 2012) implemented in Trinity-

TABLE 4

\section{ASSEMBLY STATISTICS FOR DEVELOPMENTAL TRANSCRIPTOME OF CREPIDULA ATRASOLEA}

\begin{tabular}{|c|c|c|c|}
\hline Sequencing & Total Reads & $339,134,158$ & \\
\hline Assembly & $\begin{array}{l}\text { Assembler } \\
\text { kmer size } \\
\text { Total Trinity 'transcripts' } \\
\text { Total Trinity 'genes' } \\
\text { Percent GC } \\
\text { Percent reads mapped }\end{array}$ & $\begin{array}{l}\text { Trinity } \\
25 \\
2,116,917 \\
1,914,119 \\
40.49 \\
84.63 \%\end{array}$ & $\begin{array}{l}\text { Trinity } \\
31 \\
2,131,660 \\
1,876,145 \\
40.52 \\
84.90 \%\end{array}$ \\
\hline All transcript contigs & $\begin{array}{l}\text { N50 } \\
\text { Max length } \\
\text { Mean length } \\
\text { Median length } \\
\text { Assembled bases }\end{array}$ & $\begin{array}{l}449 \\
34,495 \\
443.56 \\
324 \\
938,977,625\end{array}$ & $\begin{array}{l}484 \\
82,554 \\
471.09 \\
332 \\
1,004,208,625\end{array}$ \\
\hline Assembly Quality Assessment & $\begin{array}{l}\text { Transrate Score } \\
\text { Transcripts with ORF (Transrate) } \\
\text { RSEM-EVAL Score } \\
\text { BUSCO Score }\end{array}$ & $\begin{array}{l}0.01863 \\
120503 \\
-7690265732.40 \\
\text { C: } 96.3 \%, F: 3.7 \%, \mathrm{M}: 0.0 \%\end{array}$ & $\begin{array}{l}0.0103 \\
130112 \\
-7165569479.29 \\
\text { C: } 98 \%, F: 1.7 \%, M: 0.3 \%\end{array}$ \\
\hline Filtered Assembly Quality (TPM>1) & $\begin{array}{l}\text { Number of Transcripts Retained } \\
\text { Transrate Score } \\
\text { BUSCO Score } \\
\text { RSEM-EVAL Score }\end{array}$ & $\begin{array}{l}1,026,816 \\
0.0251 \\
\text { C: } 96.3 \%, F: 3.7 \%, M: 0.0 \% \\
-7046963013.08\end{array}$ & $\begin{array}{l}1,071,323 \\
0.0272 \\
\text { C: } 98 \%, F: 1.7 \%, M: 0.3 \% \\
-6637832850.52\end{array}$ \\
\hline Decontaminated Assembly: MCSC Pipeline & $\begin{array}{l}\text { Number of Transcripts Retained } \\
\text { BUSCO Score } \\
\text { Transrate Score }\end{array}$ & $\begin{array}{l}- \\
-\end{array}$ & $\begin{array}{l}401,824 \\
\text { C: } 92.8 \%, F: 3.2 \%, M: 4.0 \% \\
0.0119\end{array}$ \\
\hline
\end{tabular}


RNAseq (Table 4). Contig lengths were relatviely short compared to comparable assemblies from other Crepidula species (Tables 2,4 ), which may be due to the number of pooled individuals used to prepare the sequencing library and the resulting complexity of the de Bruijn graphs (Grabherr et al., 2011). Alternatively, this could be due to high transcript complexity, a large number of SNPs, or highly repetitive sequences within the transcriptome. To improve assembly quality, we filtered by transcripts per kilobase million (TPM) value to remove low quality contigs. Read quantification (TPM) was determined with kallisto (V0.43.0), which uses pseudoalignment to rapidly and accurately quantify reads (Bray et al., 2016). Testing and verification led us to remove contigs with a TPM value lower than one. This level of filtering increased the Transrate score, while maintaining the BUSCO score, indicating an improvement over the raw assembly. Based on these results, we continued annotation work using the TPM $>1$ filtered reads of the $k-31$ mer Trinity assembly.

One of the challenges of working with emerging model systems can be the difficulty of acquiring non-contaminated samples for sequencing (Kumar et al., 2013). Marine environments are contamination-prone, with potential sources of non-target sequence coming from the surrounding seawater, biofilms, and ingested algae. We therefore assessed our filtered assembly for contamination using Blobtools (Kumar et al., 2013), which uses taxonomic identification by sequence similarity, read mapping, and GC content to visualize and identify likely contaminant sequences (Fig. 6A). Although this approach is not optimized for use with transcriptomic data (Koutsovoulos et al., 2016), it provided a visual guide to probable sequence contamination. The blobplot of the filtered assembly does not show any distinct areas of likely contamination, apart from a broad range of GC content. The range of read mapping is due to the dynamic range of transcriptomic expression, rather than potential contamination. To clean the assembly, we used a Model-based Categorical Sequence Clustering (MCSC) pipeline to remove potential contaminant sequences from our assembly (Lafond-Lapalme et al., 2016). This pipeline first clusters contigs using the MCSC algorithm

Fig. 7. Counts for all level-One Gene Ontology terms of the MCSC-cleaned $C$. atrasolea developmental assembly. $B P$, biological process; MF, molecular function; CC, cellular component.
(Xiong et al., 2014), which independently groups similar contigs through multiple rounds of clustering. Following MCSC clustering, taxonomic information was incorporated, and the cluster identities were compared to a taxonomic white list (Mollusca). A white list ratio was calculated based on BLAST bitscores, and clusters with a white list ratio most similar to the selected taxonomic grouping, and largest difference from the non-white list clusters were retained. This method has been developed specifically to address contamination in transcriptome assemblies, and does not require predefined sources of contamination. The MCSC approach retained 401,824 sequences, or $37.5 \%$ of the filtered assembly. We reassessed the decontaminated assemblies for quality using BUSCO and transrate scores (Table 4), and saw a slight decrease in BUSCO score,

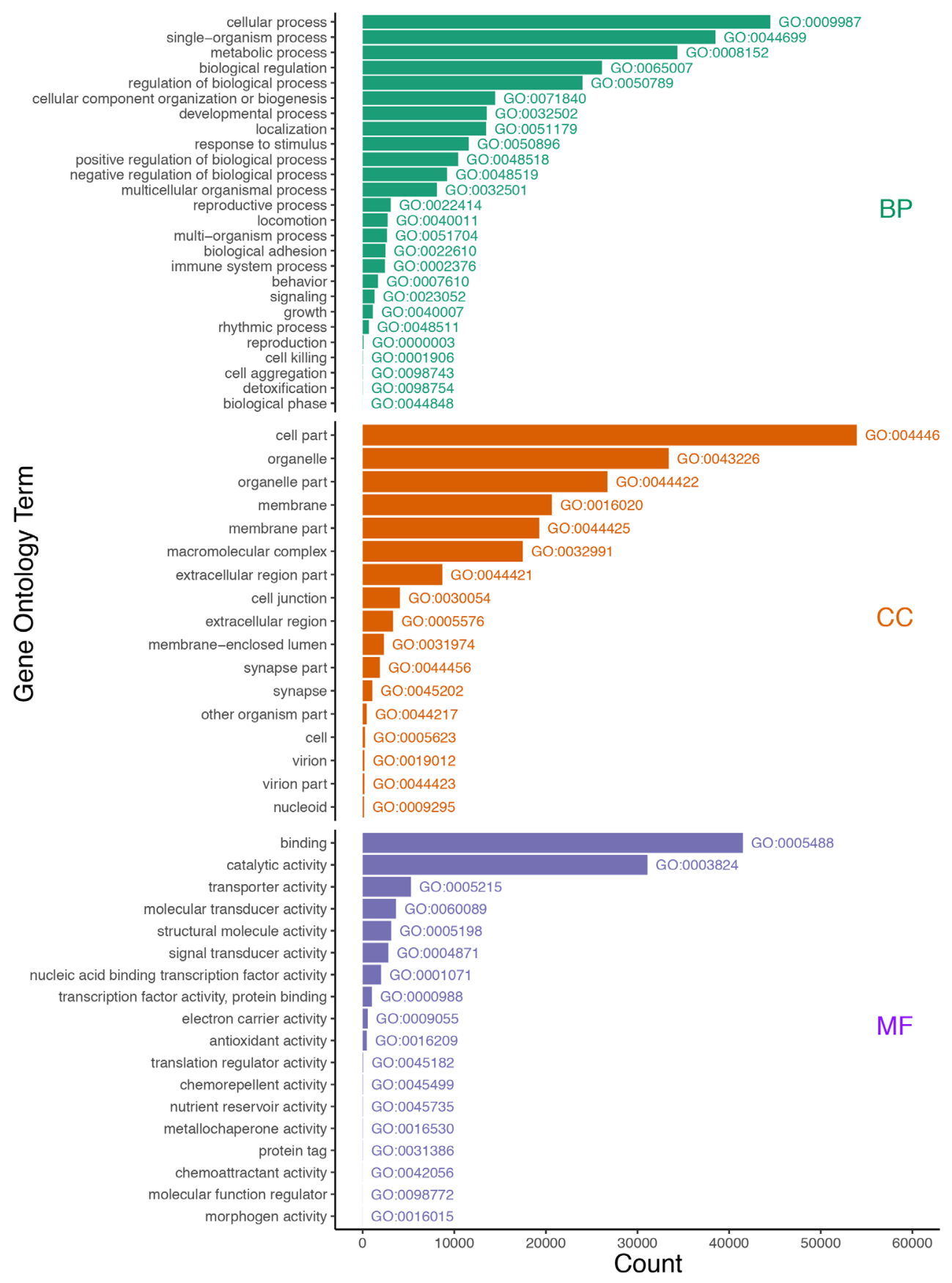


relatively few sequences were annotated, reflecting continuing challenges in working with spiralian datasets. The annotation includes results of blastx searches of the assembled contigs and blastp searches of the longest open reading frames as predicted by Transdecoder (v2.0.1, https://transdecoder.github.io/) against the Uniprot Swissprot database (rel 30-Nov-2016) using BLAST+ (v2.6.0) (Camacho et al., 2009). Only the top hits to the Uniprot database were retained. Protein domains predicted by HMMER (v3.0, Finn et al., 2011) were also added to the annotation. We also incorporated top hits from a Diamond blastx search (v0.8.5) (Buchfink et al., 2015) against the UniRef90 database (Release 2016-11) used as implemented in the MCSC decontamination pipeline. Trinotate also adds Gene Ontology and KEGG pathway information to the output based on the SwissProt database (Fig. 7). The annotation reports of the filtered and cleaned assemblies are available via the Henry lab website (http://www.life.illinois.edu/ henry/crepidula_databases.html). Raw reads are available from the NCBI SRA database under accession number (SRP114839). The cleaned assembly is available from the NCBI TSA database under the accession number (GFWJ00000000).

\section{Conclusions}

Development of $C$. atrasolea as a laboratory model of spiralian development offers numerous advantages, from ease of culturing successive generations outside of a marine setting, to large embryos that are ideal for experimental manipulation. This particular species opens the door to increasing the use of Crepidula as a model system to expand our understanding of spiralian development beyond the edge of the sea. By documenting early development, our proven laboratory rearing techniques, and assembling a transcriptome of development, we hope to expand the use of this system and provide the readers with a solid foundation from which to start their own laboratory cultures. The completed genome of $C$. atrasolea, which is currently being sequenced, will be of tremendous use, and the development of transgenic lines of these snails will permit further exploration of the fascinating biology of this system.

\section{Acknowledgements}

The authors thank Dr. Rachel Collin for suggesting that C. atrasolea would represent a convenient model system. We also thank Sherry Reed, Seabird McKeon, and other members of the Smithsonian Marine Station in Fort Pierce, FL for their assistance in collecting these animals. In addition, we thank Drs. Leslie Babonis and Mark Martindale of the Whitney Marine lab in St Augustine, FL for their assistance. We are grateful for the support provided by Dr. Alvaro Hernandez, Director of the High-Throughput Sequencing and Genotyping Unit at the Roy J. Carver Biotechnology Center, University of Illinois. The authors acknowledge the invaluable support of the National Science Foundation (NSF). JQH (JJH), KJP, MPL, CCO were supported by NSF grant IOS-1558061. MPL was supported by a Postdoctoral Fellowship from the Fonds de recherche du Québec - Nature et technologies (FRQ-NT). MPL thanks the Society for Developmental Biology for an Emerging Models Grant in support of work on C. atrasolea. DCL thanks Dr. David R. McClay for his support.

\section{References}

BOLGER A M, LOHSE M and USADEL B (2014). Trimmomatic: a flexible trimmer for Illumina sequence data. Bioinformatics 30: 2114-2120.

BRANTE A, FERNÁNDEZ M and VIARD F (2011). Microsatellite evidence for sperm storage and multiple paternity in the marine gastropod Crepidula coquimbensis.
$J$ Exp Mar Biol Ecol 396: 83-88.

BRAY N L, PIMENTEL H, MELSTED P and PACHTER L (2016). Near-optimal probabilistic RNA-seq quantification. Nat Biotech 34: 525-527.

BUCHFINK B, XIE C and HUSON D H (2015). Fast and sensitive protein alignment using DIAMOND. Nat Meth 12: 59-60.

CAHILL. A.E., JUMAN, A.R-, PELLMAN-ISAACS, A. andBRUNO, W.T. (2015). Physical and chemical interactions with conspecifics mediate sex change in a protandrous gastropod Crepidula fornicata. Biol Bull 229: 276-281.

CAHILL, A.E. and LEVINTON, J.S. (2016). Genetic differentiation and reduced genetic diversity at the northern range edge of two species with different dispersal modes. Mol Ecol 25: 515-526.

CAHILL, A.E. and VIARD, F. (2014). Genetic structure in native and non-native populations of the direct-developing gastropod Crepidula convexa. MarBiol161:2433-2443.

CAMACHO C, COULOURIS G, AVAGYAN V, MA N, PAPADOPOULOS J, BEALER $\mathrm{K}$ and MADDEN T L (2009). BLAST+: architecture and applications. BMC Bioinformatics 10 (421): 1-9.

CARRILLO-BALTODANO A and COLLIN R (2015). Crepidula slipper limpets alter sex change in response to physical contact with conspecifics. Biol Bull 229: 232-242.

CHAPARRO O R, SEGURA C J, NAVARRO J M and THOMPSON R J (2004). The effect of food supply on feeding strategy in sessile female gastropods Crepidula fecunda. Mar Biol 144: 79-87.

CHAPARRO O R, THOMPSON R J and PEREDA S V (2002). Feeding mechanisms in the gastropod Crepidula fecunda. Mar Ecol-Prog Ser 234: 171-181.

COE W R (1936). Sexual phases in Crepidula. J Exp Zool 72: 455-477.

COE W R (1938). Conditions influencing change of sex in mollusks of the genus Crepidula. J Exp Zool 77: 401-424.

COE W R (1949). Divergent methods of development in morphologically similar species of prosobranch gastropods. J Morphol 84: 383-399.

COLLIN R (1995). Sex, size, and position: A test of models predicting size at sex change in the protandrous gastropod Crepidula fornicata. Am Nat 146: 815-831.

COLLIN R (2000a). Phylogeny of the Crepidula plana (Gastropoda: Calyptraeidae) cryptic species complex in North America. Can J Zool 78: 1500-1514.

COLLIN R (2000b). Sex change, reproduction, and development of Crepidula adunca and Crepidula lingulata (Gastropoda: Calyptraeidae). Veliger 43: 24-33.

COLLIN R (2001). The effects of mode of development on phylogeography and population structure of North Atlantic Crepidula (Gastropoda: Calyptraeidae). Mol Ecol 10: 2249-2262

COLLIN R (2003a). Phylogenetic relationships among calyptraeid gastropods and their implications for the biogeography of marine speciation. Syst Biol52:618-640.

COLLIN R (2003b). The utility of morphological characters in gastropod phylogenetics: an example from the Calyptraeidae. Biol J Linn Soc 78: 541-593.

COLLIN R (2003c). Worldwide patterns in mode of development in calyptraeid gastropods. Mar Ecol-Prog Ser 247: 103-122.

COLLIN R (2004). Phylogenetic effects, the loss of complex characters, and the evolution of development in calyptraeid gastropods. Evolution 58: 1488-1502.

COLLIN R (2010). Repeatability of egg size in two marine gastropods: brood order and female size do not contribute to intraspecific variation. MarEcol-Prog Ser410:89-96.

COLLINR, CHAPARRO OR, WINKLER F and VELIZD (2007). Molecular phylogenetic and embryological evidence that feeding larvae have been reacquired in a marine gastropod. Biol Bull 212: 83-92.

COLLIN R and GRIFFIN T (2005). Indian River Lagoon Species Inventory: Crepidula atrasolea. http://www.sms.si.edu/irlspec/Crepid_atrasol.htm.

COLLIN R, MCLELLAN M, GRUBER K and BAILEY-JOURDAIN C (2005). Effects of conspecific associations on size at sex change in three species of calyptraeid gastropods. Mar Ecol-Prog Ser 293: 89-97.

COLLIN R and SALAZAR M Z (2010). Temperature-mediated plasticity and genetic differentiation in egg size and hatching size among populations of Crepidula (Gastropoda: Calyptraeidae). Biol J Linn Soc 99: 489-499.

COLLIN R and SPANGLER A (2012). Impacts of adelphophagic development on variation in offspring size, duration of development, and temperature-mediated plasticity. Biol Bull 223: 268-277.

CONKLIN E G (1897). The embryology of Crepidula: A contribution to the cell lineage and early development of some marine gasteropods. J Morphol 13: 1-226. 
DAGUIN-THIEBAUT C, LE CAM S and VIARD F (2009). Isolation of 11 microsatellite markers in Crepidula convexa (Gastropoda, Calyptraeideae) for parentage analyses. Mol Ecol Res 9: 917-920.

DUPONT L, BERNAS D and VIARD F (2007). Sex and genetic structure across age groups in populations of the European marine invasive mollusc, Crepidula fornicata L. (Gastropoda). Biol J Linn Soc 90: 365-374.

EDGECOMBE, G.D., GIRIBET, G., DUNN, C.W., HEJNOL, A., KRISTENSEN, R.M., NEVES, R,C., ROUSE, G.W., WORSAAE, K. and SØRENSEN, M.V. (2011). Higher-level metazoan relationships: recent progress and remaining questions. Org Divers Evol 11: 151-172.

ESPINOSA E P and ALLAM B (2006). Comparative growth and survival of juvenile hard clams, Mercenaria mercenaria, fed commercially available diets. Zoo Biol 25: 513-525.

FINN R D, CLEMENTS J and EDDY S R (2011). HMMER web server: interactive sequence similarity searching. Nucleic Acids Res 39: W29-W37.

GRABHERR M G, HAAS B J, YASSOUR M, LEVIN J Z, THOMPSON D A, AMIT I, ADICONIS X, FAN L, RAYCHOWDHURY R, ZENG Q, CHEN Z, MAUCELI E, HACOHEN N, GNIRKE A, RHIND N, DI PALMA F, BIRREN B W, NUSBAUM C, LINDBLAD-TOH K, FRIEDMAN N and REGEV A(2011). Full-length transcriptome assembly from RNA-Seq data without a reference genome. NatBiotech29:644-652.

HAAS BJ, PAPANICOLAOUA, YASSOUR M, GRABHERR M, BLOOD P D, BOWDEN J, COUGER M B, ECCLES D, LI B and LIEBER M (2013). De novo transcript sequence reconstruction from RNA-seq using the Trinity platform for reference generation and analysis. Nat Protoc 8: 1494-1512.

HALANYCH K M, BACHELLER J D, ANNA MARIE A A, LIVA S M, HILLIS D M and LAKE J A (1995). Evidence from 18S ribosomal DNA that the lophophorates are protostome animals. Science 267: 1641-1643.

HEJNOL A, MARTINDALE M Q and HENRY J Q (2007). High-resolution fate map of the snail Crepidula fornicata: the origins of ciliary bands, nervous system, and muscular elements. Dev Biol 305: 63-76.

HENDLER G and FRANZD R (1971). Population dynamics and life history of Crepidula convexa Say (Gastropoda: Prosobranchia) in Delaware Bay. Biol Bull141:514-526.

HENRY J J, COLLIN R and PERRY K J (2010a). The Slipper Snail, Crepidula: An emerging lophotrochozoan model system. Biol Bull 218: 211-229.

HENRY $\mathrm{J} J$ and PERRY K J (2008). MAPK activation and the specification of the D quadrant in the gastropod mollusc, Crepidula fornicata. Dev Biol 313: 181-195.

HENRY J J, PERRY K J, FUKUI L and ALVI N (2010b). Differential localization of mRNAs during early development in the mollusc, Crepidula fornicata. Integr Comp Biol 50: 720-733.

HENRY J Q (2014). Spiralian model systems. Int J Dev Biol 58: 389-401.

HENRY J Q and LYONS D C (2016). Molluscan models: Crepidula fornicata. Curr Opin Gen Dev 39: 138-148.

HENRY J Q, PERRY K J and MARTINDALE M Q (2010c). $\beta$-catenin and early development in the gastropod, Crepidula fornicata. Integr Comp Biol 50: 707-719.

HOAGLAND K (1978). Protandry and the evolution of environmentally-mediated sex change: A study of the Mollusca. Malacologia 17: 365-391.

HOAGLAND K E (1985). Genetic relationships between one British and several North American populations of Crepidula fornicatavased on allozyme studies (Gastropoda, Calyptraeidae). J Molluscan Stud 51: 177-182.

KOUTSOVOULOS G, KUMAR S, LAETSCHD R, STEVENS L, DAUB J, CONLON C, MAROON H, THOMAS F, ABOOBAKERAA and BLAXTERM (2016). No evidence for extensive horizontal gene transfer in the genome of the tardigrade Hypsibius dujardini. Proc Natl Acad Sci USA 113: 5053-5058.

KUMAR S, JONES M, KOUTSOVOULOS G, CLARKE M and BLAXTER M (2013). Blobology: exploring raw genome data for contaminants, symbionts and parasites using taxon-annotated GC-coverage plots. Front Gen 4: 1-12.

LAFOND-LAPALME J, DUCEPPE M-O, WANG S, MOFFET P and MIMEE M (2016). A new method for decontamination of de novo transcriptomes using a hierarchical clustering algorithm. Bioinformatics 33: 1293-1300.

LANGMEAD B and SALZBERG S L (2012). Fast gapped-read alignment with Bowtie 2. Nat Meth 9: 357-359.

LESOWAY M P, ABOUHEIF E and COLLIN R (2014). The development of viable and nutritive embryos in the direct developing gastropod Crepidula navicella. Int J Dev Biol 58: 601-611.

LESOWAY M P, ABOUHEIF E and COLLIN R (2016). Comparative transcriptomics of alternative developmental phenotypes in a marine gastropod. J Exp Zool B Mol Dev Evol 326: 151-167.

LI B, FILLMORE N, BAI Y, COLLINS M, THOMSON J A, STEWART R and DEWEY C N (2014). Evaluation of de novo transcriptome assemblies from RNA-Seq data. Genome Biol 15 (553): 1-21.

LYONS D C, PERRY K J and HENRY J Q (2015). Spiralian gastrulation: Germ layer formation, morphogenesis, and fate of the blastopore in the slipper snail Crepidula fornicata. EvoDevo 6: 1-24.

LYONS D C, PERRY K J, LESOWAY M P and HENRY J Q (2012). Cleavage pattern and fate map of the mesentoblast, $4 \mathrm{~d}$, in the gastropod Crepidula: a hallmark of spiralian development. EvoDevo 3: 1-26

MCDONALD K A, COLLIN R and LESOWAY M P (2014). Poecilogony in the caenogastropod Calyptraea lichen (Mollusca: Gastropoda). Invertebr Biol 133: 213-220.

NELSON D A, CALABRESE A, GREIG R A, YEVICH P P and CHANG S (1983). Long-term silver effects on the marine gastropod Crepidula fornicata. Marine Ecol. Prog. Ser. 12: 155-165.

PERRY K J and HENRY J Q (2015). CRISPR/Cas9-mediated genome modification in the mollusc, Crepidula fornicata. Genesis 53: 237-244

PERRY K J, LYONS D C, TRUCHADO-GARCIA M, FISCHER A H L, HELFRICH L W, JOHANSSON K B, DIAMOND J C, GRANDE C and HENRY J Q (2015). Deployment of regulatory genes during gastrulation and germ layer specification in a model spiralian mollusc Crepidula. Dev Dynamics 244: 1215-1248.

RICHARD J, HUET M, THOUZEAU G and PAULET Y M (2006). Reproduction of the invasive slipper limpet, Crepidula fornicata, in the Bay of Brest, France. Mar Biol 149: 789-801.

RIQUET F, BALLENGHIEN M, TANGUY A and VIARD F (2011). In silico mining and characterization of 12 EST-SSRs for the invasive slipper limpet Crepidula fornicata. Mar Genomics 4: 291-295.

RIQUET F, DAGUIN-THIÉBAUT C, BALLENGHIEN M, BIERNE $N$ and VIARD F (2013). Contrasting patterns of genome-wide polymorphism in the native and invasive range of the marine mollusc Crepidula fornicata. Mol Ecol22: 1003-1018.

RIQUET F, LE CAM S, FONTENEAU E and VIARD F (2016). Moderate genetic drift is driven by extreme recruitment events in the invasive mollusk Crepidula fornicata. Heredity 117: 42-50

RIVEST B R (1992). Studies on the structure and function of the larval kidney complex of prosobranch gastropods. Biol Bull 182: 305-323

ROMIGUIER J, GAYRAL P, BALLENGHIEN M, BERNARDA, CAHAIS V, CHENUILA, CHIARIY, DERNATR, DURETL, FAIVRE N, LOIRE E, LOURENCO J M, NABHOLZ B, ROUX C, TSAGKOGEORGA G, WEBER A A T, WEINERT L A, BELKHIR K, BIERNE N, GLEMIN S and GALTIER N (2014). Comparative population genomics in animals uncovers the determinants of genetic diversity. Nature 515: 261-263.

SHUMWAY S E, WARD J E, HEUPEL E, HOLOHAN B A, HEUPEL J, HEUPEL T and PADILLA D K (2014). Observations of feeding in the common Atlantic slippersnail Crepidula fornicata L., with special reference to the "mucus net". J Shellfish Res 33: 279-291.

SIMÃO F A, WATERHOUSE R M, IOANNIDIS P, KRIVENTSEVA E V and ZDOBNOV E M (2015). BUSCO: assessing genome assembly and annotation completeness with single-copy orthologs. Bioinformatics 31: 3210-3212.

SMITH-UNNA R, BOURSNELL C, PATRO R, HIBBERD J and KELLY S (2016). TransRate: reference free quality assessment of de novo transcriptome assemblies. Genome Res 26: 1134-1144.

SPOTTE S H (1970). Fish and Invertebrate Culture: Water Management in Closed Systems. Wiley-Interscience, New York.

TESSMAR-RAIBLEK(2003). Emerging systems: between vertebrates and arthropods, the Lophotrochozoa. Curr Opin Genet Dev 13: 331-340.

WILSON E B (1892). The cell-lineage of Nereis. A contribution to the cytogeny of the annelid body. $J$ Morphol 6: 361-480.

WILSON E B (1898). Consideration on cell-lineage and ancestral reminiscence Based on: A re-examination of some points in the early development of annelids and polyclades. Ann NY Acad Sci 11: 1-27.

WOODRUFF D S, MCMEEKIN L L, MULVEY M and CARPENTER M P (1986). Population genetics of Crepidula onyx: Variation in a Californian slipper snail recently established in China. Veliger 29: 53-63.

XIONG T, WANG S, JIANG Q and HUANG J Z (2014). A novel variable-order Markov Model for clustering categorical sequences. IEEE T Knowl Data En 26: 2339-2353. 


\section{Further Related Reading, published previously in the Int. J. Dev. Biol.}

Regeneration in spiralians: evolutionary patterns and developmental processes

Alexandra E. Bely, Eduardo E. Zattara and James M. Sikes

Int. J. Dev. Biol. (2014) 58: 623-634

https://doi.org/10.1387/ijdb.140142ab

The development of viable and nutritive embryos in the direct developing gastropod Crepidula navicella Maryna P. Lesoway, Ehab Abouheif and Rachel Collin

Int. J. Dev. Biol. (2014) 58: 601-611

https://doi.org/10.1387/ijdb.140136rc

Sipuncula: an emerging model of spiralian development and evolution

Michael J. Boyle and Mary E. Rice

Int. J. Dev. Biol. (2014) 58: 485-499

https://doi.org/10.1387/ijdb.140095mb

Variation in spiralian development: insights from polychaetes

Elaine C. Seaver

Int. J. Dev. Biol. (2014) 58: 457-467

https://doi.org/10.1387/ijdb.140154es

Ins and outs of Spiralian gastrulation

Deirdre C. Lyons and Jonathan Q. Henry

Int. J. Dev. Biol. (2014) 58: 413-428

https://doi.org/10.1387/ijdb.140151dl

Establishing the germline in spiralian embyos

Nicole Rebscher

Int. J. Dev. Biol. (2014) 58: 403-411

https://doi.org/10.1387/ijdb.140125nr

Spiralian model systems

Jonathan Q. Henry

Int. J. Dev. Biol. (2014) 58: 389-401

https://doi.org/10.1387/ijdb.140127jh

\section{Contemporary Spiralian Developmental Biology}

Jonathan Henry

Int. J. Dev. Biol. (2014) 58: 385-387

https://doi.org/10.1387/ijdb.140289jh

5 yr ISI Impact Factor $(2013)=2.879$
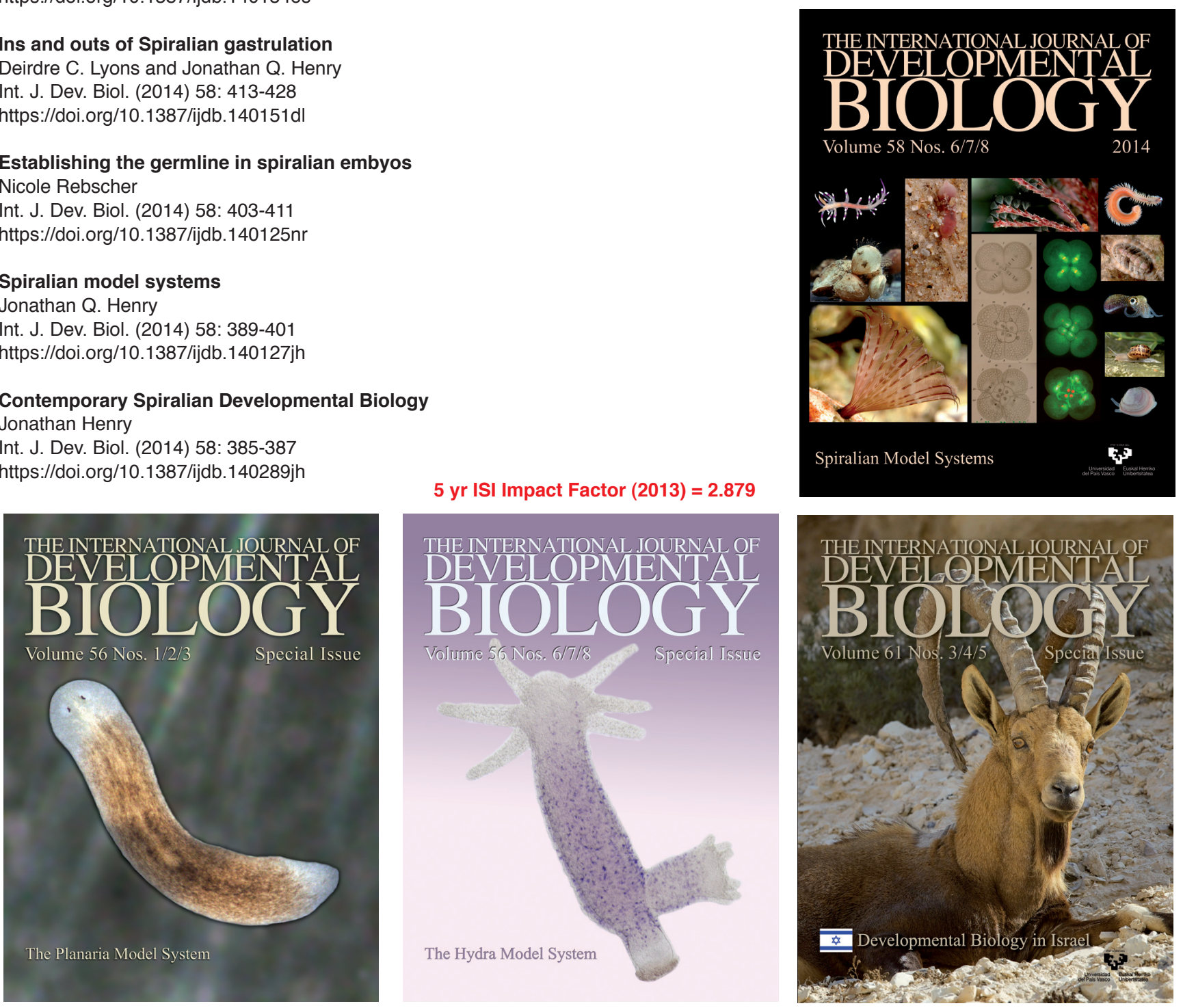